\title{
LED bulbs technical specification and testing procedure for solar home systems
}

\author{
Alfonso Gago Calderón , Luis Narvarte Fernández , Luis Miguel Carrasco Moreno , \\ Javier Serón Barba
}

Fundación Solitec, CMareas Bajas No. 19, Poligono Industrial Alameda, ZIP 29006 Malaga, Spain

Institute of Solar Energy, Polytechnic University of Madrid, Spain

University of Malaga, Spain

\begin{abstract}
A B S T R A C T
The definition of technical specifications and the corresponding laboratory procedures are necessary steps in order to assure the quality of the devices prior to be installed in Solar Home Systems (SHS). To clarify and unify criteria a European project supported the development of the Universal Technical Standard for Solar Home Systems (UTSfSHS). Its principles were to generate simple and affordable technical requirements to be optimized in order to facilitate the implementation of tests with basic and simple laboratory tools even on the same SHS electrification program countries. These requirements cover the main aspects of this type of installations and its lighting chapter was developed based on the most used technology at that time: fluorescent tubes and CFLs. However, with the consolidation of the new LED solid state lighting devices, particular attention is being given to this matter and new procedures are required. In this work we develop a complete set of technical specifications and test procedures that have been designed within the frame of the UTSESHS, based on an intense review of the scientific and technical publications related to LED lighting and their practical application. They apply to lamp reliability, performance and safety under normal, extreme and abnormal operating conditions as a simple but complete quality meter tool for any LED bulb.

These tests have been applied to a group of 14 low-cost direct current LED bulbs and the accomplishment of the proposed requirements is analyzed.
\end{abstract}

Abbreviations: CC, constant current; CFLs, Compact Fluorescent Lamps; EMI, electromagnetic interference; HP, high power; HB, high brightness; IC, integrated circuit; Li-ion, lithium-ion; PCB, printed circuit board; PVRE, photovoltaic rural electrification; SHS, Solar Home System; UTSfSHS, Universal Technical Standard for Solar Home Systems

* Corresponding author. Tel.: + 349523301 51; fax: + 34952038672.

E-mail address: alfonso_gago@solydi.com (A. Gago Calderón). 


\section{Introduction}

LED lamps have introduced a new way of electric light generation from an electronic source which is overpassing conventional technologies traditional barriers of light efficiency and reliability [1] and have become the optimum solution for solar home systems considering "cost effectiveness and robustness" [2]. For example, the luminous flux of 8-W Compact Fluorescent Lamps (CFLs) is around $400 \mathrm{~lm}$ while low/medium class LED bulbs can overpass this value with only $5 \mathrm{~W}$, and is expected to reach soon peak efficacies over $200 \mathrm{~lm} / \mathrm{W}$ and to reduce their basic cost up to $95 \%$ by the year $2030[3,4]$.

Moreover, this type of devices are built without any amount of hazardous elements like mercury or lead which is one of "the most imperative features of solar-powered LED lighting" installations [5]. Comparing CFL and LED bulbs on equivalent quality basis with respect to the expected lifetimes, the first ones have, on average, 12 times higher potential environmental impact due to reduced hazardous and rare metals [6] and there are many investigation projects to minimize the usage of hazardous metals in the LED manufacturing process [7]. These bulbs, when broken, must be treated as any other electronic device with no battery such as any small home appliance: preferably repairing them and, when it is not possible, disassembling them and reusing or recycling their different pieces. Many national and local policy and legislation are being created along this basic principle [8].

Concerning the specific area of the Solar Home Systems (SHSs), the off-grid electric lighting solutions have evolved in the last decades from the initial combination of fluorescent lamps and small incandescent ones $[9,10]$ to CFLs $[11,12]$ and finally to LED bulbs that are expected to grow at a very significant rate, especially in developing countries [13]. For example there is an estimation of 40-45\% year-on-year growth in Africa through 2015 [14]. There are some particular characteristics that make it very easy to relate the SHSs and the LED lamps. The electronic nature of the semiconductor crystal, which acts as the new light source, works on low DC voltage and can be easily adapted to solar energy generators and batteries. Thus, this make this technology a very promising opportunity in SHS, substituting the current CFLs.

In the past, the quality of SHSs in general, and CFLs in particular, was impelled with the elaboration of many dedicated norms designed by different entities that, in many cases showed important differences in their requirements and specifications [15-24]. In this situation, the collaboration between worldwide experts financed by the EU crystalized in the Universal Technical Standard for Solar Home Systems (UTSfSHS) in order to unify technical and procedure criteria [25]. This norm inspired other specifications like the one of the Bolivian IDTR program [26,27] or the Peruvian PER project [28].
Now it is necessary to adapt the UTSFSHS to the new LED lamps and, consequently, this paper proposes a specific technical specification for this kind of lamps when used in decentralized DC Photovoltaic Rural Electrification (PVRE) applications together with its required quality tests.

The proposed technical specifications and testing procedures have been applied to a representative collection of different models of $12 \mathrm{~V}_{\mathrm{DC}}$ LED bulbs acquired in the current SHS market. Results are discussed and they illustrate the relevance of the technical specification proposed in this work and the current state of the art of LED bulb lamps.

\section{Review of the current standard for LED lamps technical specifications}

As well as with the CFL bulbs as the LED technology is becoming more popular there are appearing several specification lists to ensure the reliability, performance and security for lighting devices based on these electronic circuits. Many of them are generated for general porpoise product [29-33] but there are also several specifically generated for off-grid DC equipment [34-36].

These specifications are based on general lighting technical regulations and on manufacturers and testing laboratories and international agencies recommendations based on the reliability and performance knowledge generated with standard electronic components and that has been used to generate specific test for LED encapsulations. For example, the lifetime of a LED lamp is defined by the Illuminating Engineering Society (IES) in their standards LM-79 and LM-80 and Energy Star has developed the TM-21 procedure guide to foresee the lumen maintenance of the semiconductor crystals over the time along with its current input and working temperature [37]. These proposed tests are long time consuming (LM-80 asks for at least a $6.000 \mathrm{~h}$ test for good long term predictions) and require of expensive measurement equipment. Many laboratories in developing countries are not prepared to prepare and realize many of the tests proposed in these specifications lists. Thus, it is necessary to generate a reviewed list of requirements that guarantee the performance of LED lamp on SHS and off-grid installations and that can be revised by local technicians without requiring long periods of time or nonaffordable equipment by the capacity of that type of laboratories.

\section{Technical specifications}

The quality of LED lamps for rural electrification should be judged in terms of its reliability, performance and safety, and so 
these categories will be used to present the proposed specifications in the next sections.

In this case we have considered LED bulbs working in a Solar Home System with lead-acid batteries; the most used PV rural application around the world. In the last few years PV rural installations called "Pico Systems" have been developed. They are low power systems (between 1 and $10 \mathrm{Wp}$ ) for mobile lighting and mobile charging $[38,39]$. These systems are designed following the criteria of offering $60 \mathrm{~lm}-5 \mathrm{~h}$ per day. This value is defined as the minimum lighting requirement by the Sustainable Energy for All Initiative (SE4ALL) launched by the General Secretary of the United Nations [40]. To achieve these performance the required capacity installed is between 0.15 and $110 \mathrm{Ah}[41,42]$, values that are easily obtained with Li-ion batteries. However, these requirements and values are quite lower than the normal requirements for a SHS with an average power installed between 10 and $100 \mathrm{Wp}$ and much higher battery capacity [39]. Lead-acid battery units can offer between 1 and $1400 \mathrm{Ah}$. [42].

LED bulbs are a massive-production retrofit concept of a conventional incandescent or CFL bulb that can be used on the same luminaries and sockets already present on SHS. They allow a low cost easy evolution to this new LED technology. Fig. 1 shows the basic configuration of a LED bulb lamp detailing their main components.

Following the format of the UTSFSHS [25], the technical specifications have been classified into three groups to consider the required flexibility to be adapted to the different economic circumstances of the countries where decentralized PVRE programs are carried out:

- Compulsory (C): Minimum accepted performance.

- Recommended (R): Good set of working parameters.

- Suggested (S): Maximum performance.

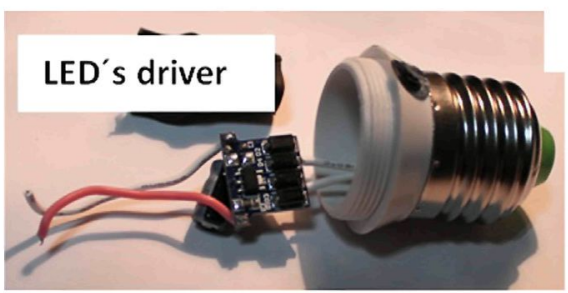

LED's crystal

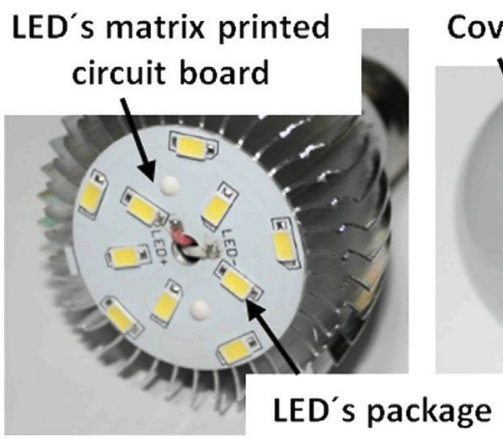

Cover
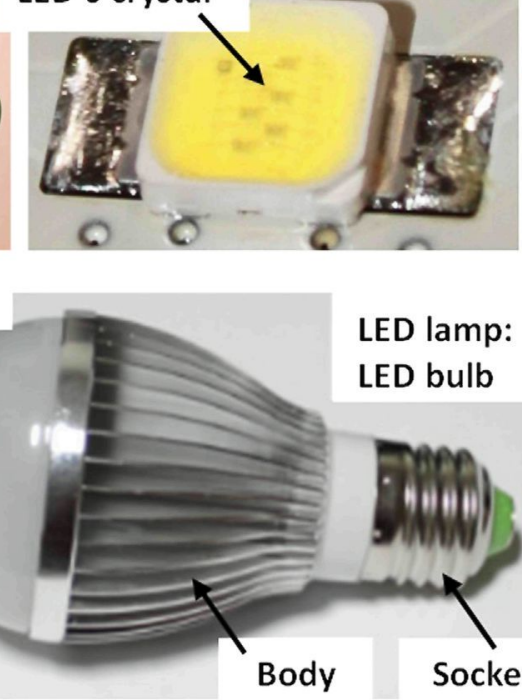

LED lamp: LED bulb

Fig. 1. LED bulb's components description.

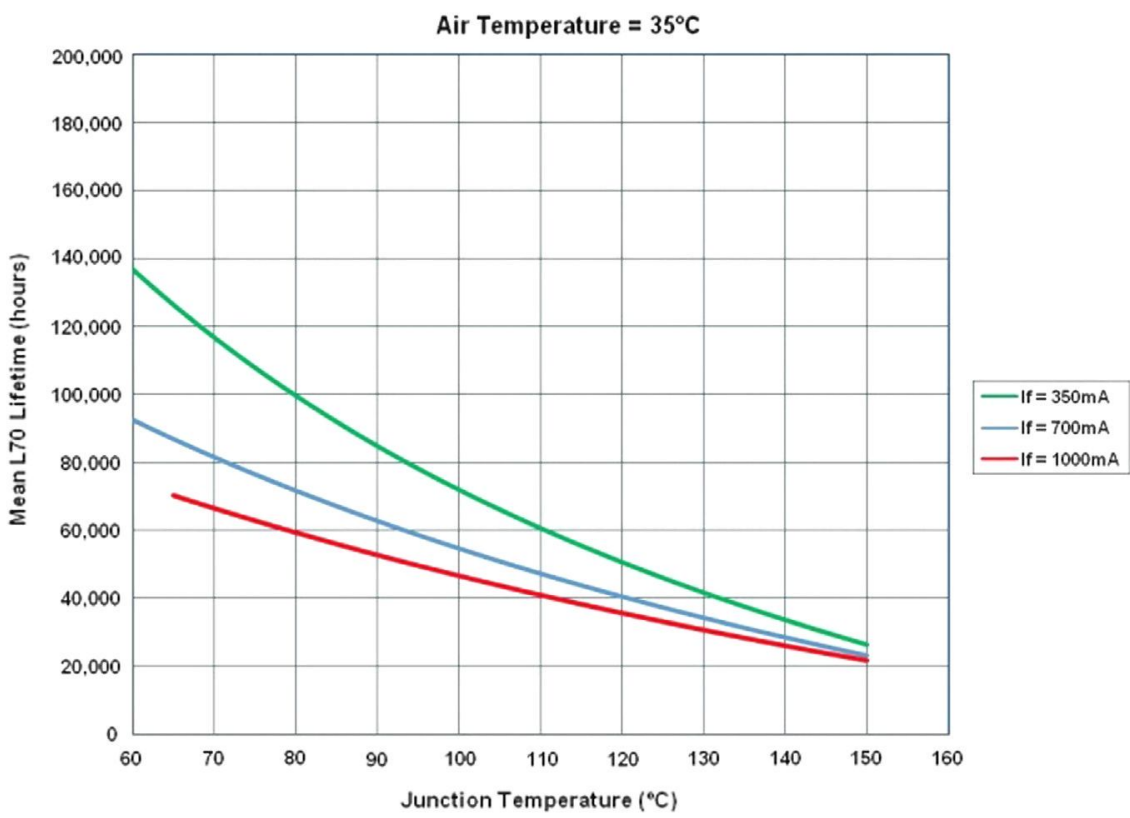

Fig. 2. Example of LED lifetime expectation dependency with semiconductor crystal's working temperature and input current. Source: Cree [24]. 
The technical specifications have been proposed taking into account the compatibility with the norms of charge regulator, wiring and battery of the UTSfSHS. In particular, the considered battery is lead-acid as the most common model due to its low cost, simplicity of manufacturing and life cycle considerations $[43,44]$ although the adaptation to Li-ion batteries is not complex, as it will be probably necessary to redefine only the voltage range of the system widen it up to cover the full working range of this technology, and will be the objective of future works.

\subsection{Reliability}

Special attention is given to reliability as it is the key design factor in rural electrification. On CFLs the main reliability concern is related to the degradation of their electrodes due to usage and turn on/off cycles. However, in LED bulbs, due to the electronic nature of this technology, reliability is highly related with the working temperature. Studies from manufacturers, independent scientific groups and testing laboratories [45-51] show how LED lifetime is dramatically reduced as their working temperature increases. One manufacturer's long term lifetime information of a significant LED present on the market depending on it semiconductor crystal working temperature is shown in Fig. 2.

The first source to check the LED reliability is the information given by the manufacturer about the fulfillment of these standards. So,

o The bulb's manufacturer must provide the information of the LED's model and manufacturer (R).

o The LED model used must have a published LM-80 report (IES-LM80) (R).
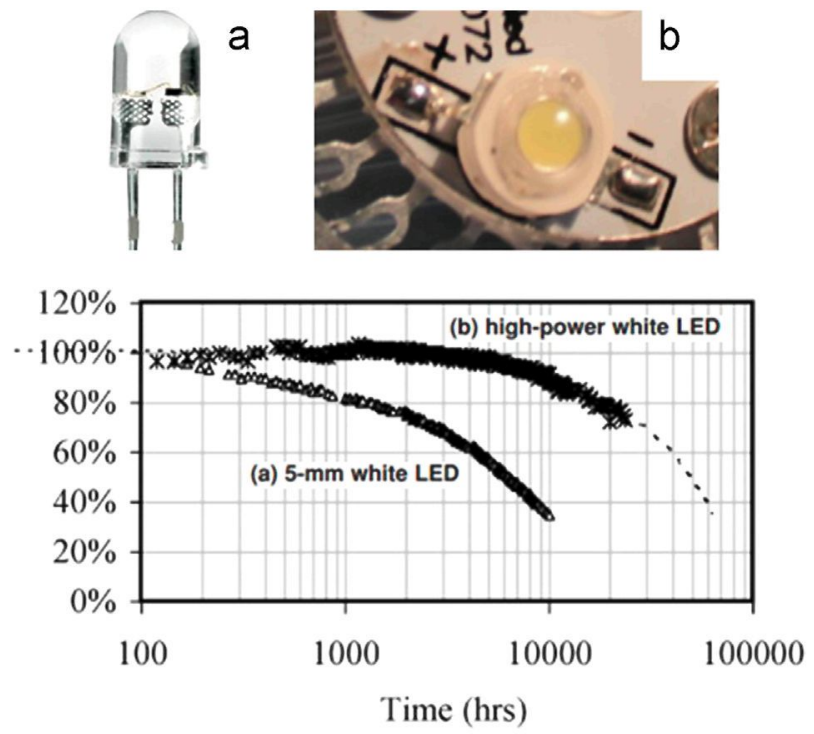

Fig. 3. Comparison of LED's long term lifetime expectation depending on the type of LED package and their construction methodology.
The working temperature of the semiconductor crystals is very difficult to measure due to their covers and packages. However, this value can be estimated according to the temperature measurement of the LED matrix's printed circuit board (PCB) and using average thermal resistance values depending on the type of the different models of LED packages. These values range from 5 to $10^{\circ} \mathrm{C} / \mathrm{W}$ for High Power (HP) lighting classified LED ( $0.5 \mathrm{~W}$ or higher nominal power single devices with dedicated or independent thermal relief pad underneath the package) to values over $50^{\circ} \mathrm{C} / \mathrm{W}$ proper of High Brightness (HB) displays application devices. The worst case is found in the $5 \mathrm{~mm}$ epoxy throughhole packages where the thermal resistance achieves the highest values. Many different studies such as the one from Nerendan et al. [52] show how the estimated lifetime expectation of these two different types of LED packages offer completely different lifetime performance as detailed in Fig. 3.

Consequently:

- No full epoxy LED package must be used on the bulb'S LED matrixes (C).

Internal LED temperatures around $85^{\circ} \mathrm{C}$ in bulbs with specific lighting HP LED packages conduct to temperature values on the PCB between 65 and $75^{\circ} \mathrm{C}$. However, with HB LEDs the expected temperature value are around $45-55^{\circ} \mathrm{C}$ [53]. If the measure taken is below these values it indicates that the heat may not be properly evacuated from inside the LED's crystals. If the measure is over that ranges the semiconductor crystal is most probably over $85^{\circ} \mathrm{C}$ and the reliability of the lamp is compromised [54-56]. So,

The LED matrix's temperature nearby the LEDs must be between 65 and $75^{\circ} \mathrm{C}$ for High Power LEDs and between 45 and $55^{\circ} \mathrm{C}$ for High Brightness LEDs at nominal voltage and $25{ }^{\circ} \mathrm{C}$ of ambient temperature $(\mathbf{C})$.

The Integrated Circuits (ICs), the inductors and electrolytic capacitors of the LEDs drivers are thermal dependent on their lifetime expectancy and on their working behavior. Their temperature must be always under their absolute maximum rating, so that no catastrophic failures are expected.

To guarantee a good thermal evacuation from the bulbs, they must have the necessary elements to conduct the heat from the LED packages to the surrounding air. To minimize energy consumption the generalized solution is to use its main body as a heat sink so that a natural convection process cools the bulbs [57].

In the market they can be found two main body designs as presented in Fig. 4:

- Plastic bodies: They avoid direct contact with the electronic components and the heat evacuation from the driver is based on some holes in the body as they have a very low heat dissipation capacity.
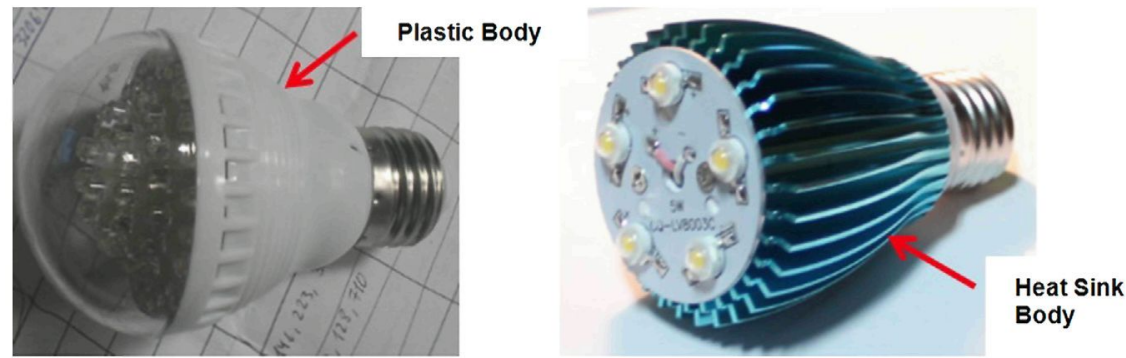

Fig. 4. Bulb's LED matrixes: (left) 5 mm epoxy through-hole packages and plastic case (right) SMD thermal PAD high power LED package and metallic heat sink. 
- Metallic or ceramic bodies: These materials have a high thermal power transmission capability. The heat from the LED is evacuated by direct conduction and the complete system is cooled by the ambient air.

Thus, in order to guarantee high long term lifetime reliability:

- The bulb must have a metallic or ceramic heat sink (R).

The temperature of the heat sink should not be below $45^{\circ} \mathrm{C}$ (at $25^{\circ} \mathrm{C}$ ambient temperature) as it would show that there is not a good heat evacuation channel on the bulbs and all the energy is kept on the semiconductor crystal or in the integrated circuits [58]. So,

o Bulb's heat sink temperature must be at least $20^{\circ} \mathrm{C}$ higher than the ambient temperature with the LED bulb working at its nominal power $(\mathbf{C})$.

o The temperature of the heat sink must not be over $70^{\circ} \mathrm{C}$ (at $25^{\circ} \mathrm{C}$ ambient temperature) to avoid overheating in the LED's electronic driver $(\mathbf{C})$.

To complete an exhaustive thermal reliability analysis, it is necessary to disassemble the bulb to identify all the ICs, inductors, and electrolytic capacitors required by the LED drivers (as shown in Fig. 1). Their technical documentation will give some initial basic information about their reliability and lifetime estimation. So, it will be required:

- All the electronic components of the bulb's LED driver must have a temperature maximum rating of $85^{\circ} \mathrm{C}$ or higher $(\mathbf{C})$.

- All the electronic components of the bulb's LED driver must have a temperature maximum rating of $105^{\circ} \mathrm{C}$ or higher (S).

These electronic components must be properly isolated from the heat sink for electrical safety reasons but they also should allow a good heat evacuation to guarantee reliability [59]. There are some non-expensive solutions (such as self-vulcanizing rubber cover) but some high performance materials improve bulb's driver cooling (for example polyimide film cover). So,

- The electronic driver must be properly isolated from the heat sink of the bulb with a specific protection cover $(\mathbf{C})$.

- The electronic driver must be properly isolated from the heat sink of the bulb with a specific protection cover with high heat transfer properties ( $\mathbf{R})$.

As indicated, optimum heat dissipation is generated by a conduction process from the LED to the surface of the lamp where this energy is finally extracted through non-force convection to the open ambient air. This contact channel needs to be well finished so that heat can flow properly. Manufacturing errors such as bad assembly unions (like the one shown on Fig. 5) can generate high lifetime reductions and, in some cases, fatal failures [56]. So,

- No visible manufacturing assembly failures on heat transfer elements are allowed $(\mathbf{C})$

Furthermore, if the thermal pad underneath the package of the LED is not properly solder, the heat generated inside the LED bulb has not an optimal solid path to be evacuated [56]. This is easily observed with a thermal camera but hard to observe otherwise. In this case we recommend trying to solder out the components though their anode and cathode accessible pins. If the underneath pad is properly solder with solder past and a reflow oven it will be impossible to move away the LED.

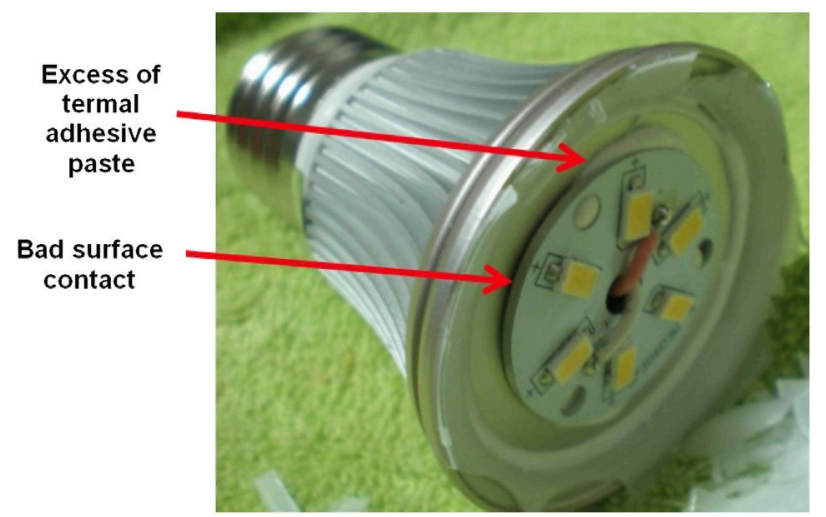

Fig. 5. Example of bad contact assembly procedure of a LED PCB with the bulb heat sink.

- All the PADs of the LED's packages must be properly soldered (C).

As these previous standard tests analyze just the different components of the LED bulb and not the reliability of the complete bulb equipment [60], the LED bulb will have to fulfill the following specification.

- LED bulbs must maintain at least $90 \%$ of initial light output after $1000 \mathrm{~h}$ of a continuous turn on status at nominal voltage and $\mathrm{Ta}=25^{\circ} \mathrm{C}(\mathbf{C})$.

\subsection{Performance}

The electrical performance of LED bulbs should be evaluated according to their efficiency and to a good match between their electrical characteristics and the SHS requirements.

Regarding their electrical characteristics, it is a common practice to advertise the LED bulbs with the direct diode's nominal power used in the devices (i.e. five $1 \mathrm{~W}$ LEDs $\rightarrow 5 \mathrm{~W}$ bulb) and they do not take into account the electrical losses of the drivers and the input electronic protections. A large difference between these two values can lead to a bad sizing of the elements of a SHSs. So,

- The LED bulb's real power consumption must be within a $10 \%$ tolerance range around its nominal value (at nominal voltage and $25{ }^{\circ} \mathrm{C}$ of ambient temperature) (C).

o The LED bulb's real power consumption must be within a $5 \%$ tolerance range around its nominal value (at nominal voltage and $25{ }^{\circ} \mathrm{C}$ of ambient temperature) (R).

Furthermore, many $12 \mathrm{~V}$ bulbs of the market are designed to be used both on DC or AC input voltage. Thus they are rather thought for some grid-connected homes with a $12 \mathrm{~V}$ transformer rather than for an off-grid SHS with batteries, and they cannot work at the complete range of operating values specified by the UTSfSHS [25]. Thus, considering the voltage range for a lead-acid battery:

- The LED bulb must not show any misperformance in the voltage range from $-15 \%$ to $+25 \%$ of the SHS nominal voltage at $25{ }^{\circ} \mathrm{C}$ of ambient temperature $(\mathbf{C})$.

Regarding efficiency, the most used comparison parameter is the ratio between the total light output and its power consumed, measured in lumen per watt. Even though this measure does not cover the advantage of the directional nature of the emission of 
the LED and their lower dependency with the reflectors of their luminaries [61], we still will keep this ratio as reference.

Based on the state of art and the expected evolution of the high power LED technology [62-65], the LED bulbs efficiency requirements at nominal voltage and $25^{\circ} \mathrm{C}$ of ambient temperature should be:

o The luminous yield for the total LED bulb system must be $\geq 60$ $\mathrm{Im} / \mathrm{W}(\mathbf{C})$.

o The luminous yield for the total LED bulb system must be $\geq 80$ $\mathrm{Im} / \mathrm{W}(\mathbf{R})$.

o The luminous yield for the total LED bulb system must be $\geq 100 \mathrm{~lm} / \mathrm{W}(\mathbf{S})$.

Finally, a correct performance must be assured even in extreme ambient temperatures. So,

- No light flickering or instability must be present on extreme ambient temperature $\left(-10^{\circ} \mathrm{C}\right.$ and $\left.50^{\circ} \mathrm{C}\right)(\mathrm{C})$.

\subsection{Safety}

In order to ensure that the bulb is built under environmental friendly conditions and will respond to the expected parameters of the technology the manufacturer must guarantee that all the components used and the manufacturing substances comply with the WEEE or the RoHS directives [66].

- The LED bulb's must be certified by the manufacturer to comply with the WEEE or the RoHS directives $(\mathbf{C})$.

The reliability of the equipment depends on their ability to withstand normal and abnormal operation conditions: LED bulbs must assure their own long-term integrity but also the user's safety. The LED bulbs must be designed to avoid the following risky situations:

- The bulb's body must not allow that any electric active element can be touched by persons.

- The LED bulb must have protections against humidity or insect entrance.

It is worth to note that, to improve heat dissipation, many LED bulb designs show many open spaces to easy air flown and so improve LED cooling. These open spaces must not compromise the user's security or allow that insects, dust or other elements may get inside the bulb reducing its functionality or endurance [50].

Because of the design of a bulb with an Edison's socket, active parts are on the outside surface of the device, so all the considerations about protections will be done with the light emitting surface and the main body (plastic or metallic) of the bulbs.

If we consider personal safety on a DC device an equivalent IP20 rate is enough as it covers that a finger ( $12.5 \mathrm{~mm}$ of diameter) cannot touch the bulb driver or the LED matrix [67]. However, the protection against humidity and insects needs of a harder requirement level that will depend on the expected placement of the lamp [68].

o The LED bulb's cover and main body must have an equivalent IP protection rate of at least IP22 for indoor usage, or IP43 for outdoor usage (C).

o The LED matrix and the driver's electronic components must be covered with a protective coating against moisture, dust, or chemicals (R).

The E27 Edison screw is a common bulb connection system both for $A C$ and $D C$ input power devices. This makes possible to place low voltage $D C$ bulbs on $A C$ networks what implies an important electrical risk in case of wrong usage. So, in accordance with the norms about wiring in the UTSFSHS [25],

\section{- A durable DC input voltage label must be visible on the bulbs (C).}

Furthermore, the devices must be tested to be safe in case of inversion of polarity of the input power.

o The LED bulb must be protected against destruction when the supply voltage is reverse-poled $(\mathbf{C})$.

o The LED bulb must work if the supply voltage is reverse-poled (R).

The bulb must be able to survive to abnormal working conditions of a SHS installation and/or wrong performance of any other SHS components. This is the case, for example, if the charge regulator allows abnormal voltages on the system close to the solar panel's open circuit values (for a $12 \mathrm{~V}$ SHS installation, a $21 \mathrm{~V}$ voltage supply) [69]. So,

- The device must have a safe behavior and do not break over a period of, at least, $30 \mathrm{~min}$, a solar panel's open circuit voltage $(\boldsymbol{C})$.

Finally, the generation of electromagnetic interference (EMI) on other electronic devices over the air or the electric line must be below certain level so that the user does not perceive any inconvenience when the LED bulbs are turned on [70]. Thus,

The LED bulb must not produce radio frequency interference $(\mathbf{C})$.

\subsection{List of specifications}

As a summary, the complete list of LED bulb's specifications is shown on Table 1. It is worth to underline that this set of specifications has been conceived to be used in contractual frameworks.

\section{Quality control procedures}

The procedures to check the fulfillment of the LED bulb's technical specifications are described in the following subsections. All these procedures have been designed under the principle of simplicity and affordability, so that they can be applied by local laboratories within the reach of the countries where PVRE programs are carried out, equipped only with the basic electrical instrumentation [71].

All the LED bulbs tested under these procedures must be working under stable conditions. Prior to turn on any LED bulb, both the LED matrix and its driver are at ambient temperature but, as soon as the LEDs start emitting, the temperatures of their crystals raise and so this changes the behavior of the bulb. It requires between 20 and $30 \mathrm{~min}$ reaching a stable working state. For this reason all the measures of the following proposed tests must be taken after a pre-heat period of at least $30 \mathrm{~min}$. [72]

\subsection{Reliability: working temperature}

Many concerns and requirements about the reliability of the bulbs related to their working temperature can be verified with a simple direct visual inspection of the bulb's package, its body and the components placed inside it (CLED5, CLED7, CLED8, RLED3, RLED4 and SLED1).

However, the rest of requirement verifications need of several specific tests. As explained before, direct temperature measurements are hard to obtain and, consequently, to verify: the semiconductor's crystal is usually under a solid case and the electronic driver of the 
Table 1

Proposed UTSfSHS's technical requirements for LED bulbs.

Compulsory
CLED1 No full epoxy LED package must be used on the bulb's LED matrixes.

CLED2 The LED matrix's temperature nearby the LEDs must be between 65 and $75^{\circ} \mathrm{C}$ for High Power LEDs and between 45 and $55{ }^{\circ} \mathrm{C}$ for High Brightness LEDs at nominal voltage and $25^{\circ} \mathrm{C}$ of ambient temperature.

CLED3 Bulb's heat sink temperature must be at least $20^{\circ} \mathrm{C}$ higher than the ambient temperature with the LED bulb working at its nominal power.

CLED4 The temperature of the heat sink must not be over $70^{\circ} \mathrm{C}$ (at $25^{\circ} \mathrm{C}$ ambient temperature) to avoid overheating in the LED's electronic driver.

CLED5 All the electronic components of the bulb's LED driver must have a temperature maximum rating of $85{ }^{\circ} \mathrm{C}$ or higher.

CLED6 The electronic driver must be properly isolated from the heat sink of the bulb with a specific protection cover.

CLED7 No visible manufacturing assembly failures on heat transfer elements are allowed.

CLED8 All the PADs of the LED's packages must be properly soldered.

CLED9 LED bulbs must maintain at least $90 \%$ of initial light output after $1000 \mathrm{~h}$ of a continuous turn on status at nominal voltage and Ta $=25{ }^{\circ} \mathrm{C}$.

CLED10 The LED bulb's real power consumption must be within a $10 \%$ tolerance range around its nominal value (at nominal voltage and $25{ }^{\circ} \mathrm{C}$ of ambient temperature)

CLED11 The LED bulb must not show any misperformance in the voltage range from $-15 \%$ to $+25 \%$ of the SHS nominal voltage at $25{ }^{\circ} \mathrm{C}$ of ambient temperature.

CLED12 The luminous yield for the total LED bulb system must be $\geq 60 \mathrm{~lm} / \mathrm{W}$.

CLED13 No light flickering or instability must be present on extreme ambient temperature $\left(-10^{\circ} \mathrm{C}\right.$ and $\left.50^{\circ} \mathrm{C}\right)$.

CLED14 The LED bulb's must be certified by the manufacturer to comply with the WEEE or the RoHS directives.

CLED15 The LED bulb's cover and main body must have an equivalent IP protection rate of at least IP22 for indoor usage, or IP43 for outdoor usage.

CLED16 A durable DC input voltage label must be visible on the bulbs.

CLED17 The LED bulb must be protected against destruction when the supply voltage is reverse-poled.

CLED18 The device must have a safe behavior and do not break over a period of, at least, 30 min, a solar panel's open circuit voltage.

CLED19 The LED bulb must not produce radio frequency interference.

\section{Recommended}

RLED1 The bulb's manufacturer must provide the information of the LED's model and manufacturer.

RLED2 The LED model used must have published a LM-80 report (IES-LM-80).

RLED3 The bulb must have a metallic or ceramic heat sink.

RLED4 The electronic driver must be properly isolated from the heat sink of the bulb with a specific protection cover with high heat transfer properties.

RLED5 The LED bulb's real power consumption must be within a $5 \%$ tolerance range around its nominal value (at nominal voltage and $25{ }^{\circ} \mathrm{C}$ of ambient temperature)

RLEDG The luminous yield for the total LED bulb system must be $\geq 801 \mathrm{~m} / \mathrm{W}$.

RLED7 The LED matrix and the driver's electronic components must be covered with a protective coating against moisture, dust, or chemicals.

$R \boldsymbol{R E D S}$ The LED bulb must work if the supply voltage is reverse-poled.

\section{Suggested}

SLED1 All the electronic components of the bulb's LED driver must have a temperature maximum rating of $105{ }^{\circ} \mathrm{C}$ or higher.

SLED2 The luminous yield for the total LED bulb system must be $\geq 100 \mathrm{~lm} / \mathrm{W}$.
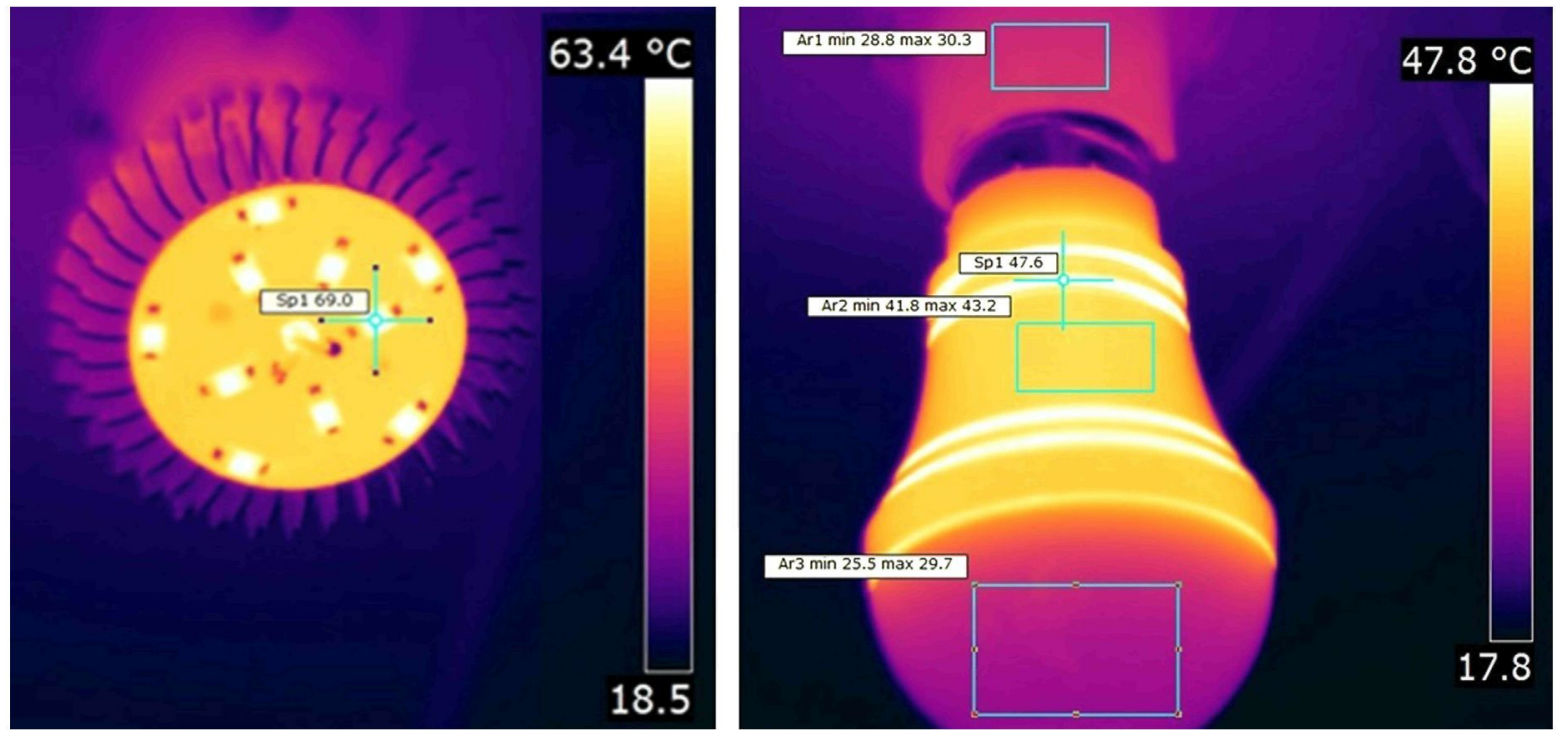

Fig. 6. LED's matrix and heat sink temperature measurement with thermal camera.

lamp in the majority of the cases is not easily accessible. However, some measures of the bulb's PCBs and the heat sinks offer a significant approximation of this value.

Based on the practice, these values can be measured either with a thermal imaging camera or with a cheaper physical contact sensor that allow checking if these temperatures are within the margin specified by the corresponding technical specifications (CLED2-CLED4). Two thermal example pictures from LED bulbs are shown in Fig. 6.

\subsection{Performance}

\subsubsection{Power consumption}

The power consumption (CLED10) is calculated powering on the LED lamp at its nominal bulb's input voltage and at $25^{\circ} \mathrm{C}$ ambient measuring the current used by the lighting device. This can be measured with an independent electric meter device or a calibrated variable power supply with an electric current indicator This same test set is used to measure the current required and the 
performance of the bulbs in all the battery working voltage range (CLED11).

\subsubsection{Extreme ambient conditions}

It is necessary to evaluate the behavior of the bulb (CLED13) as a complete end device on extreme cold and warm situations: $5{ }^{\circ} \mathrm{C}$, $-10^{\circ} \mathrm{C}$ and $50^{\circ} \mathrm{C}$. All the thermal test measures must be done without any forced ventilation system that may be acting over the LED so that the heat sink of the LED lamp works on the same ambient conditions it would have in a common indoor placement without a forced convection help. It is necessary to check:

- The switch-on process.

- Its working stability.

- Any significant changes on their behavior from nominal situations.

As cold ambient temperature allows better light efficiency and lumen maintenance, it is only necessary to analyze the startup process of the electronic driver along all the battery voltage working range (for $12 V_{D C}$ systems: $10-15 V_{D C}$ in a $1 \mathrm{~V}$ step discretization). In the warm temperature case, the switch-on power and the working stability must be checked. Furthermore, both on warm and cold cases, the LED bulb must not suffer any irreversible damage. Thus, after working at such temperatures during $1 \mathrm{~h}$, the correct operation at $25^{\circ} \mathrm{C}$ must be checked again.

We have used a climatic chamber that can be configured to work on the three specified ambient temperature. However it is possible to obtain similar results using a conventional fridge with freezer chamber and an oven with temperature regulators.

\subsubsection{Efficiency}

To calculate precisely the luminance output value (CLED12, RLED6 y SLED2), complex equipment are required such as:

- An integration sphere: That allow to find the lumens emitted by the lamp.
- A goniophotometer: That gives also the radiation diagram of the tested lamp.

These two systems are expensive and fragile equipment and hard to find in the countries where PVRE programs are developed. Thus, we pretend to find out a simple and inexpensive system to obtain a good approximated value of this parameter.

A wide set of LED bulbs have been tested with a goniophotometer that belongs to the University of Malaga (UMA) [73] and we have calculated all their irradiance diagrams. This data has helped us to consider that most of the LED bulbs correspond to two main types of radiation pattern:

- Lambertian: with a sphere-type light emitting pattern that covers a range of approximately $120^{\circ}$ from its vertical axis. This type of shape belongs to the "snowcone" shape bulbs. Depending on the type of lamp cover (transparent or diffused) they have no emission on the north hemisphere or a small amount due to reflection respectively (one significant example of a Lambertian bulb aspect and its emission diagram example is presented in Fig. 7).

- Toroid: with a solid interior. This shape belongs to candle and corn cob bulbs (one example of a Toroid bulb aspect and its emission diagram is presented in Fig. 8).

To calculate the real lumens being emitted by the bulbs without using and integration sphere or a goniophotometer, we have used the same measurement equipment than the one proposed by Egido et al. [71]. This is a black box with the following main elements (its general aspect and schematic is presented in Fig. 9):

- 2 centered and symmetric bulb socket for a reference and a testing bulb.

- 2 mobile covers to isolate each of the lamps paced on the box.

- A lux meter placed at its bottom side that can be moved along a calibrated track on the base of the box.
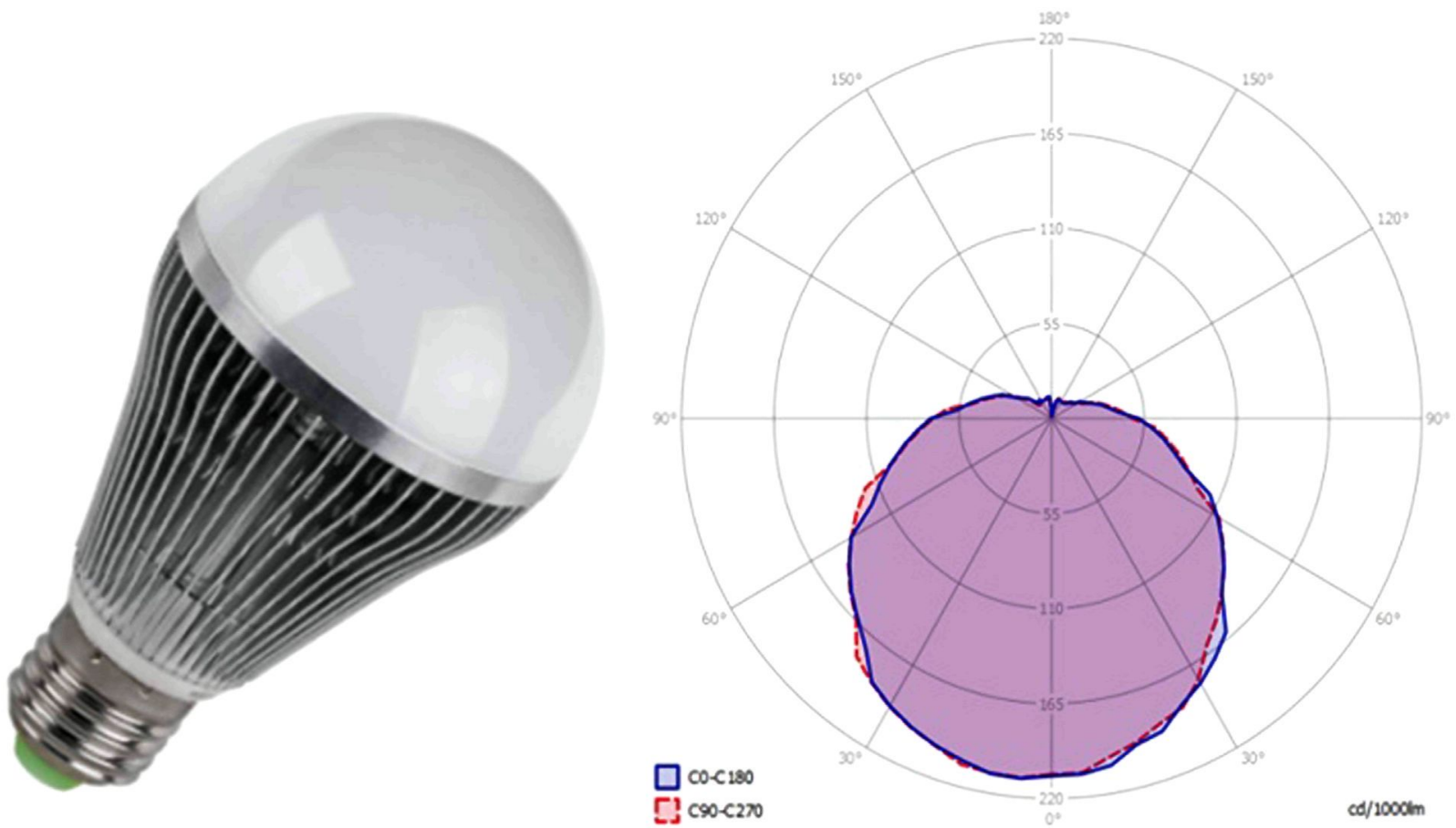

Fig. 7. Snowcone led bulbs and its associated typical lambertian radiation pattern. 

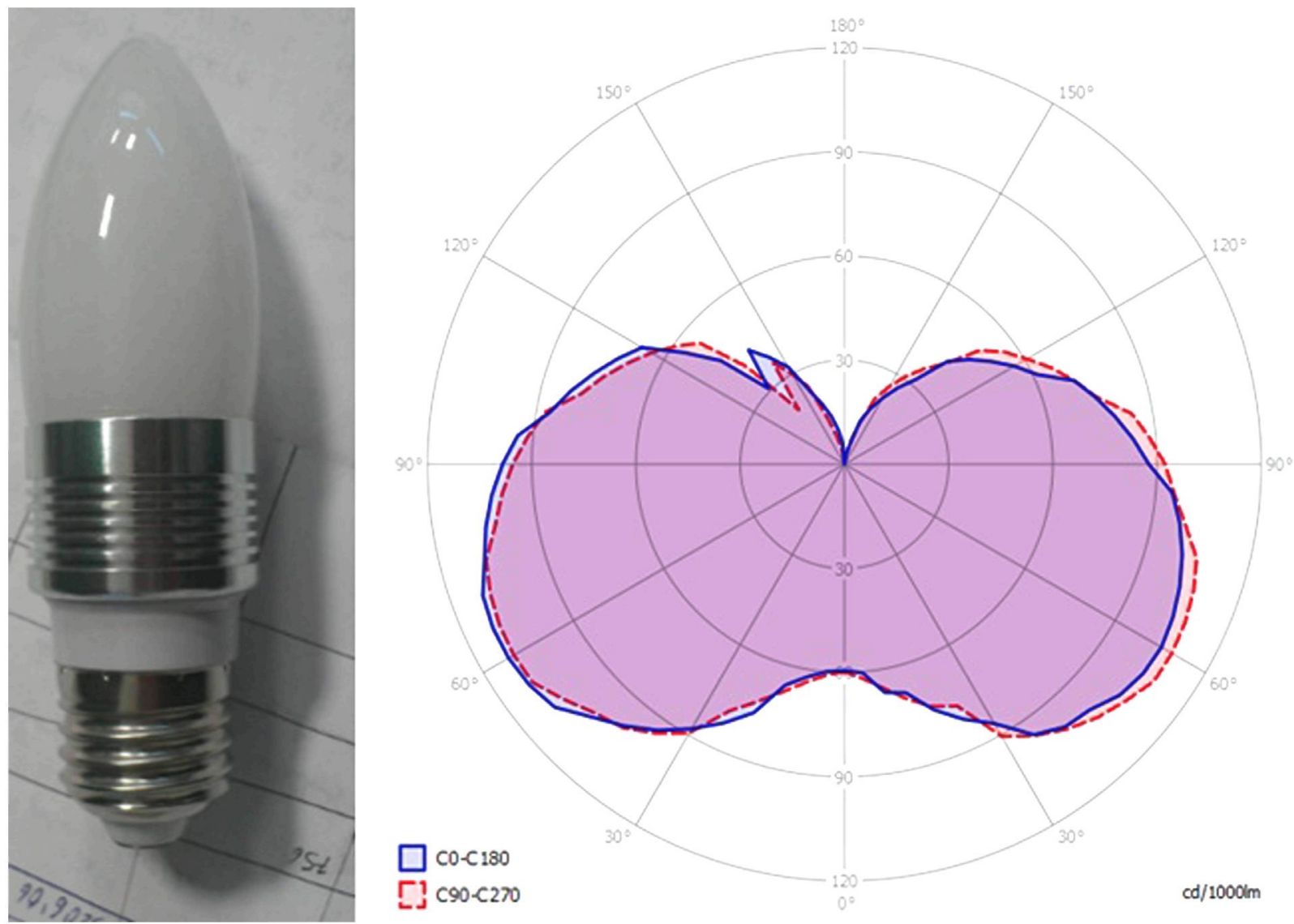

Fig. 8. Candle and corn cob bulbs and their associated typical toroid radiation pattern.
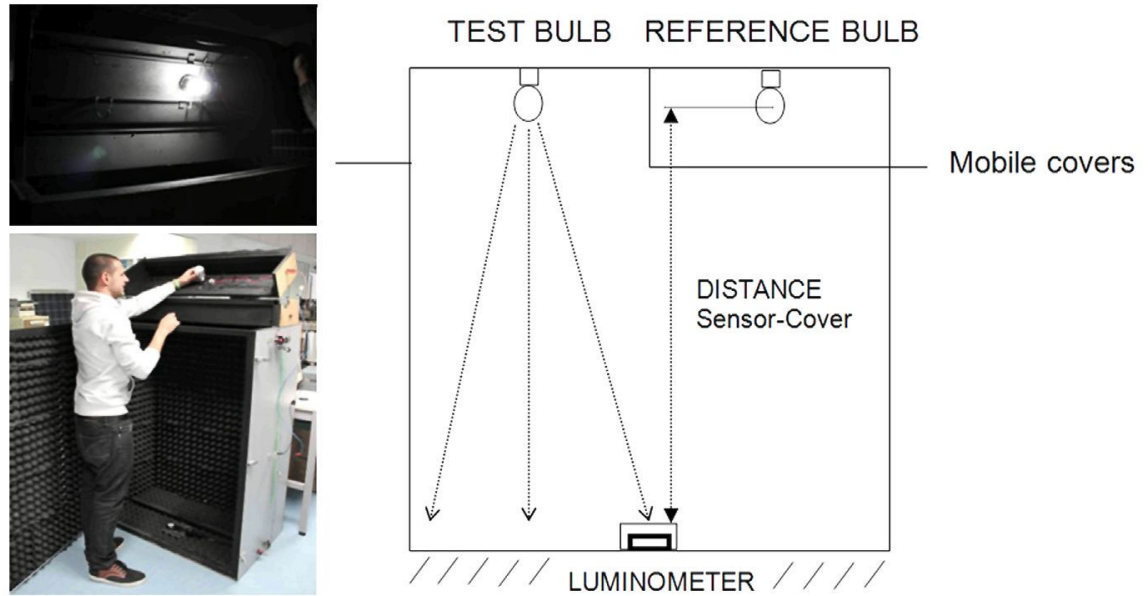

Fig. 9. Black box luminance test device and its schematic diagram.

The box height must be greater than 10 times the size of the bulbs so that they can be considered from the measurement device as a single point emitter [71].

Taking several measures along the longitudinal axis of the box's base looking for the maximum lux value allows finding the radiation pattern of a tested LED lamp and to select the appropriate LED bulb reference. Comparing the illuminance obtained with the black box and the previously known lumens of the chosen reference bulb, it is possible to approximate the lumens emitted by the tested bulb. This value is calculated based on a linear relationship between the highest value of lux measured and the lumens of the tested bulb and its reference.

Maximum normalized luxs (test bulb) Lumens (test bulb) $\overline{\text { Maximum normalized luxes (reference bulb) }}=\overline{\text { Lumens (reference bulb) }}$

As expressed on the previous formula, the maximum lux values used must be normalized depending on the different sizes of the bulb's bodies and, consequently, on the different distances sensor-bulb cover.

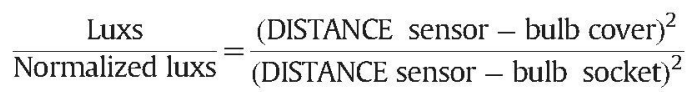


It can be observed in Table 4 of Section 4, that the maximum error of this method when compared with the goniophotometer measurement is just $5 \%$.

\subsection{Safety}

As well as with the working temperature requirements, some specifications can be visually checked (CLED6, CLED14 and RLED7). Furthermore, to verify a good protection for human safety and against humidity and insect entrance (CLED15), the bulbs can be tested as follow:

- Indoor (IP22 equivalent): Placing drops of water and allowing the displacement by gravity along the light emitting zone cover and the main body. After the test the bulb's surface is dried with a mop and then disassembled. No water can be found inside [67].

- Outdoor (IP43 equivalent): Water is sprayed with a diffuser along all the surface of the light emitting zone cover and the main body. After the test the bulb's surface is dried with a mop and then disassembled. No water can be found inside [67].

Furthermore, the devices must be tested to be safe in case of inversion of the power polarization (CLED17 and RLED8). The bulbs must be powered with the two possible polarity combinations given by the E27 screw, and see if the bulbs bright normally on both cases and if in the wrong polarity case, the lamp simply does not turn on or it suffers some type of damage: overheating, capacitors destruction.

Moreover, to check the protection against solar panel open-circuit voltage (CLED18), the bulbs must be powered with an abnormal $21 \mathrm{~V}$ input for a period of $30 \mathrm{~min}$ [69]. It is necessary to measure the input current values in order to evaluate the power consumed. The bulb may consume a close to nominal power or increase this value. In this second case, after the time indicated on the test the bulb must have a proper functionality on normal input voltage conditions.
Finally, the lighting equipment must not interfere with any other appliance of the house (CLED19). A very simple procedure to test this feature is to use a commercial radio playing a regular emission on the two extreme regions and in the middle of the wavelength radio reception range. The radio will be powered initially with the same SHS line than the bulb and secondly with independent batteries. There must be no perceptible interference on the radio emission placed either very close to the lamps (within less than a meter), and also with a $2 \mathrm{~m}$ and a $5 \mathrm{~m}$ distance from each other [25].

\section{Application to the quality control of 14 representative LED lamp models of the current market.}

A set of 14 units of LED bulb from different manufactures have been analyzed according to the tests and specifications presented. The prescriptions used to choose the devices to be tested are:

- Nominal power: between 3 and $5 \mathrm{~W}$.

- Input voltage: $12 \mathrm{~V}_{\mathrm{DC}}$.

- Socket system: E27 (Edison screw).

- Low individual cost: < 10 \$US (1 unit sample price).

At least 5 units of each model are needed in order to be fully analyzed as several test procedures may finish with the destruction of the bulb. Their main characteristics are summarized in Table 2.

\subsection{Reliability}

The documentation offered by the manufacturers of our selected bulbs is limited to basic electric information printed on their selling box and some technical specifications listed on the web page of the manufacturer: color temperature, power and voltage input range. However, little more information further than this is available.

Table 2

Description of the bulbs used in this test procedure.

\begin{tabular}{|c|c|c|c|c|c|c|c|c|c|c|c|c|c|c|}
\hline & \multicolumn{14}{|c|}{ Lamp model $-12 V_{D C}$} \\
\hline & 1 & 2 & 3 & 4 & 5 & 6 & 7 & 8 & 9 & 10 & 11 & 12 & 13 & 14 \\
\hline Nominal power $(W)$ & 3.0 & 3.0 & 3.0 & 3.0 & 3.0 & 5.0 & 3.0 & 3.0 & 5.0 & 3.0 & 3.0 & 5.0 & 5.0 & 3.0 \\
\hline Cost (1 unit \$US) & 2.10 & 3.60 & 2.90 & 3.90 & 3.20 & 6.30 & 4.10 & 3.10 & 7.40 & 3.70 & 3.60 & 4.65 & 4.50 & 7.50 \\
\hline
\end{tabular}
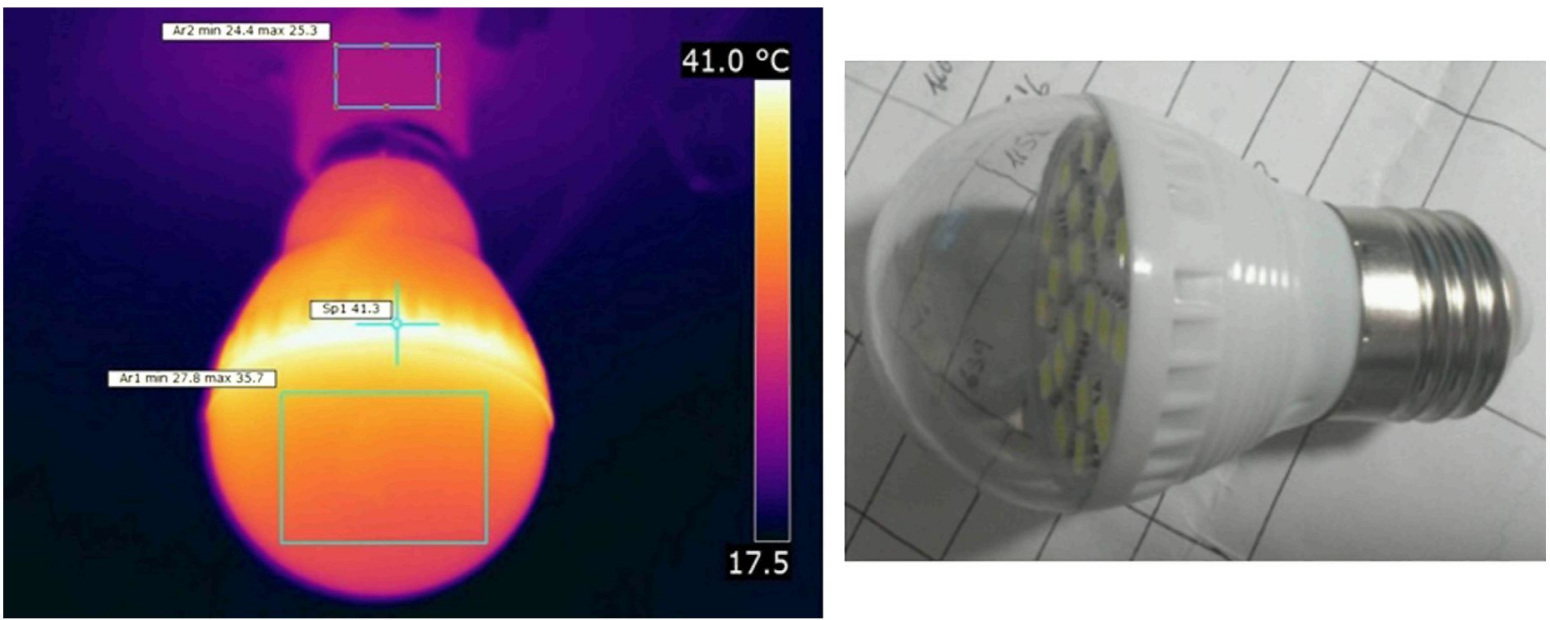

Fig. 10. Thermal image (left) of a lamp with a bad plastic heat sink (right), generating poor heat dissipation from the LEDs. 
All of them have a similar structure of screw and cover that can be easily disassembly without special tools so that the LED's matrix and its driver (with all their components) can be analyzed individually.

All the electronic components found are standard and can be easily identified by the references marked on their packages. Their data sheets with their nominal and absolute maximum rated working parameters, temperature ranges and long term lifetime analysis have been found on the internet. All the component's temperature specifications have been analyzed and are adequate to the working range of low power LED bulbs.

A thermograph camera (Fluke Ti25) has been used to check their temperatures. The results are that just one lamp (model 6)

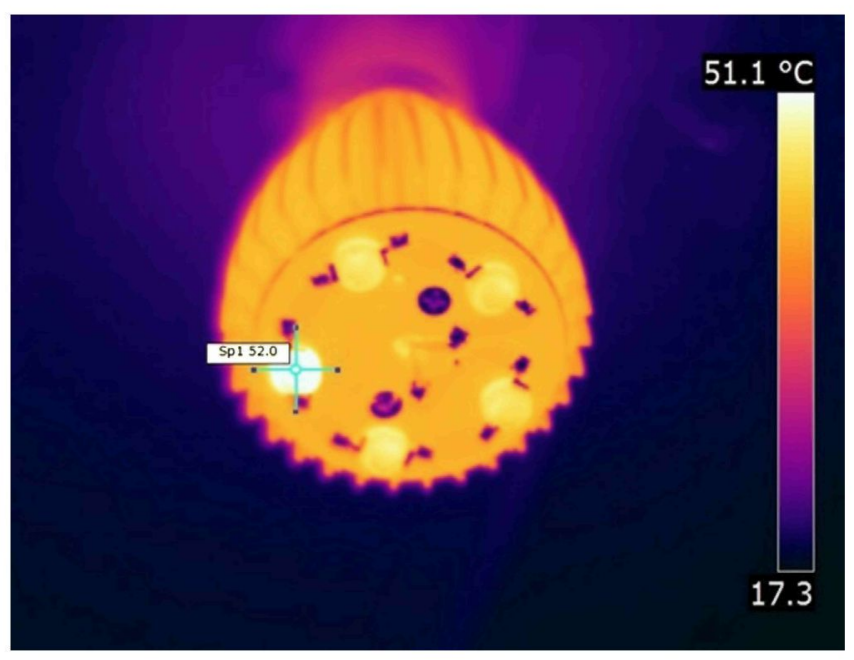

Fig. 11. LED assembly error implies very high individual component's temperatures. failed in CLED2 and lamps models 1 and 3 failed CLED3. All of the lamps fulfilled CLED4.

Note that all the LED bulbs are driven on constant current (CC) and are low power devices, so the heat generated on them is not excessive and is kept under control by the electronic driver. The exceptions are found on two bad heat transfer bodies made with plastic (RLED4), the temperature measure of one of these bulbs is shown in Fig. 10 (where the temperature of its body barely reach $40{ }^{\circ} \mathrm{C}$ ), and with manufacturing failures as bad thermal pad soldering (CLED8). In Fig. 11 we show a bulb where one LED with this solder problem has a higher temperature than the rest of the diodes.

Finally, LED bulbs have been tested turned on during a $1.000 \mathrm{~h}$ period and the maximum lux value has been registered before and after the process. The illuminance depreciation measured (according to CLED9) is shown in Fig. 12.

\subsection{Performance}

The input power of the bulbs has been measured for the nominal $12 \mathrm{~V}_{\mathrm{DC}}$ setup after a 30 min preheat process and these values have been compared with the reference given by their manufacturers. The deviations founds are summarized in Fig. 13. 13 out of 14 bulbs consume more than their nominal values, and in eight cases, more than the allowed by the proposed technical specifications.

The behavior with a 10 and $15 \mathrm{~V}_{\mathrm{DC}}$ input voltage is summarized on Table 3. The electronic drivers on all the lamps focus on generating a CC for the LEDs with a variable input power range. On many of the $3 \mathrm{~W}$ bulbs the drivers do not manage to generate the nominal current of the LEDs on low input voltages and the power and the luminance falls down. Moreover, one electronic drivers could not handle properly a $15 \mathrm{~V}$ input and this bulb started to flash and other bulb have the same problem but with a $10 \mathrm{~V}$ input.

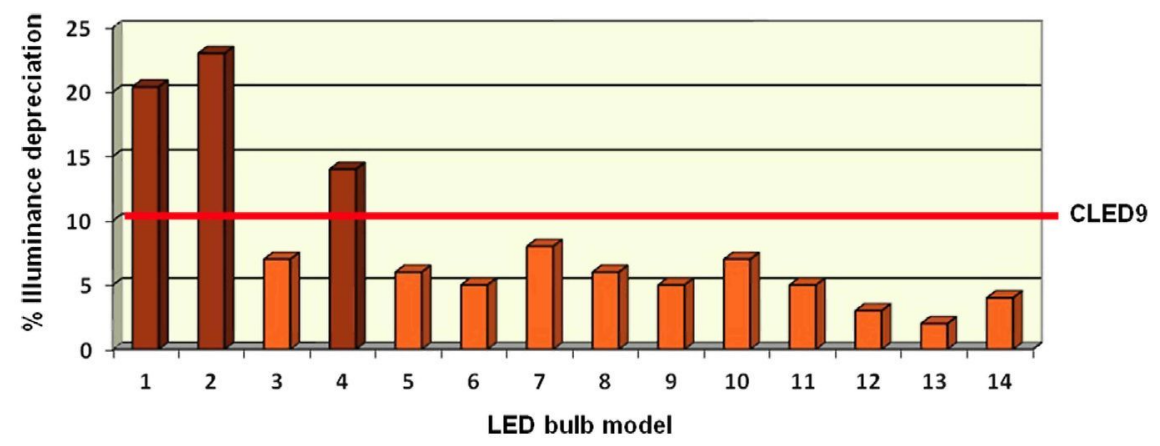

Fig. 12. Bulb's $1000 \mathrm{~h}$ light output depreciation results.

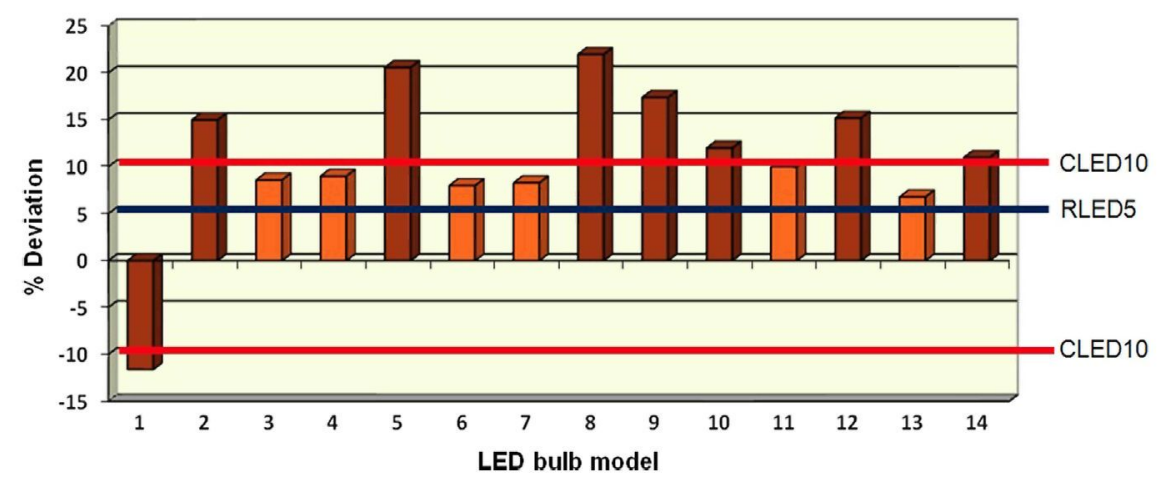

Fig. 13. Deviation of the real power consumption measured from the nominal indicated value. 
Table 3

Accomplishment of the requirements related to input voltage range.

\begin{tabular}{|c|c|c|c|c|c|c|c|c|c|c|c|c|c|c|}
\hline \multirow[t]{2}{*}{ Power $(W)$ at } & \multicolumn{14}{|c|}{ Lamp model } \\
\hline & 1 & 2 & 3 & 4 & 5 & 6 & 7 & 8 & 9 & 10 & 11 & 12 & 13 & 14 \\
\hline $10 \mathrm{~V}$ & 2.32 & 1.4 & 1.52 & 1.54 & 1.53 & - & 1.4 & 1.65 & 6.08 & 1.6 & 1.05 & 6.0 & 5.63 & 1.4 \\
\hline $12 \mathrm{~V}$ & 2.65 & 3.45 & 3.26 & 3.27 & 3.62 & 5.4 & 3.25 & 3.66 & 5.87 & 3.36 & 3.3 & 5.76 & 5.34 & 3.33 \\
\hline $15 \mathrm{~V}$ & 2.65 & 3.24 & 3.15 & 3.7 & 3.59 & 5.3 & 3.25 & - & 5.76 & 3.3 & 3.3 & 5.4 & 5.14 & 3.37 \\
\hline CLED11 & $\sqrt{ }$ & $\sqrt{ }$ & $\sqrt{ }$ & $\sqrt{ }$ & $\sqrt{ }$ & & $\sqrt{ }$ & & $\sqrt{ }$ & $\sqrt{ }$ & $\sqrt{ }$ & $\sqrt{ }$ & $\sqrt{ }$ & $\sqrt{ }$ \\
\hline
\end{tabular}

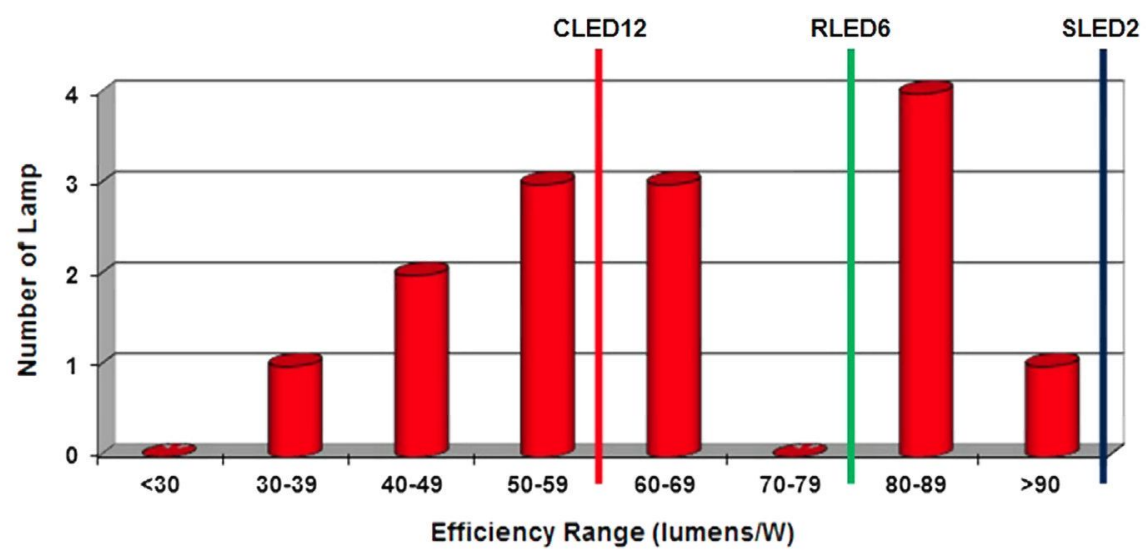

Fig. 14. Bulb's test set efficiency range distribution.

Table 4

Comparison between bulb's lumens calculated and estimated with the black box methodology.

\begin{tabular}{rlllr}
\hline Bulb & Radiation model & $\begin{array}{l}\text { Lumens measured } \\
\text { (goniophotometer) }\end{array}$ & Lumenes estimated & $\begin{array}{c}\text { Error (lumens } \\
\text { estimated vs } \\
\text { measured) (\%) }\end{array}$ \\
\hline $\mathbf{1 0}$ & Snowcone opal & \multicolumn{1}{c}{$\begin{array}{l}\text { Efficiency } \\
\text { (lumens } \\
\text { measured/W) }\end{array}$} \\
$\mathbf{1 1}$ & Snowcone opal & 295 & Reference & 83 \\
$\mathbf{1 2}$ & Snowcone opal & 473 & 278.706 & 90.11 \\
$\mathbf{1 3}$ & Snowcone opal & 419 & 457.991 & 3.28 \\
$\mathbf{8}$ & Snowcone opal & 274 & 431.208 & -2.83 \\
$\mathbf{6}$ & Snowcone opal & 205 & 273.796 & 0.07 \\
$\mathbf{4}$ & Snowcone opal & 173 & 213.980 & -4.20 \\
$\mathbf{2}$ & Snowcone opal & 166 & 169.191 & 2.25 \\
$\mathbf{9}$ & Snowcone transparent & 282 & 166.462 & -0.28 \\
$\mathbf{7}$ & Snowcone transparent & 227 & Reference & 58 \\
$\mathbf{3}$ & Snowcone transparent & 213 & 217.761 & 51 \\
$\mathbf{1}$ & Snowcone transparent & 271 & 223.695 & 48 \\
$\mathbf{5}$ & Toroide - candle & 166 & 268.434 & 36 \\
$\mathbf{1 4}$ & Toroide - corn cob & 214 & Reference & -4.78 \\
\hline
\end{tabular}

The bulbs have been also tested on the complete voltage working range of $10-15 \mathrm{~V}_{\mathrm{DC}}$ placed inside a HERAES-VÖTSCH $\mathrm{GmbH}$ thermal cabinet. The power supply was placed outside the camera that allows measuring the input bulb's voltage and current. The LED bulb tested showed no significant abnormal behaviors rather than the same ones detected on $25^{\circ} \mathrm{C}$ ambient temperature tests. The main remarkable aspect is that at $25^{\circ} \mathrm{C}$ these two units failed just on the border values of the testing range (10 and $15 \mathrm{~V}$ ) and with a warmer ambient temperature they failed also within the voltage's range: at $11.5 \mathrm{~V}$ (bulb 6) and at $13 \mathrm{~V}$ (bulb 8).

Regarding the efficiency test, three different comparison blocks were generated: snowcone with opal cover surface, snowcone with transparent or spotted cover surface and candle - corn cob bulbs. The results are described on Table 4 and in Fig. 14. Just 8 units fulfill the compulsory requirement (CLED12) and only 5 the recommended one (RLED6). The difference between the values obtained with the goniophotometer and those obtained through the lux estimation methodology are in 13 out of 14 bulbs below a $5 \%$.

The main raison to explain the extreme differences between efficiencies measured is the performance offered by the specific LED model used in each bulb. To reinforce this conclusion we have changed the LED matrix of the bulb number 3 ( $3 \mathrm{~W}$ and $65 \mathrm{~lm} / \mathrm{W}$ output) with a high performance LED matrix PCB: 3 high power CREE MX-6, $4500^{\circ} \mathrm{K}$ with a data sheet binning definition of $107 \mathrm{~lm}$ (@300 mA \& Tj $25{ }^{\circ} \mathrm{C}$ with a light output reduction of an $85 \% @ \mathrm{Tj}$ : $85^{\circ} \mathrm{C}$ ) [74]. The same bulb with this new LED matrix has obtained 


\begin{tabular}{|c|c|c|c|c|c|c|c|c|c|c|c|c|c|c|}
\hline & \multicolumn{14}{|c|}{ Lamp model $-12 \mathrm{~V}_{\mathrm{DC}}$} \\
\hline & 1 & 2 & 3 & 4 & 5 & 6 & 7 & 8 & 9 & 10 & 11 & 12 & 13 & 14 \\
\hline \multicolumn{15}{|l|}{ Reliability } \\
\hline CLED1 & & $\sqrt{ }$ & $\sqrt{ }$ & $\sqrt{ }$ & $\sqrt{ }$ & $\sqrt{ }$ & $\sqrt{ }$ & $\sqrt{ }$ & $\sqrt{ }$ & $\sqrt{ }$ & $\sqrt{ }$ & $\sqrt{ }$ & $\sqrt{ }$ & $\sqrt{ }$ \\
\hline CLED2 & $\sqrt{ }$ & $\sqrt{ }$ & $\sqrt{ }$ & $\sqrt{ }$ & $\sqrt{ }$ & & $\sqrt{ }$ & $\sqrt{ }$ & $\sqrt{ }$ & $\sqrt{ }$ & $\sqrt{ }$ & $\sqrt{ }$ & $\sqrt{ }$ & $\sqrt{ }$ \\
\hline CLED3 & & $\sqrt{ }$ & & $\sqrt{ }$ & $\sqrt{ }$ & $\sqrt{ }$ & $\sqrt{ }$ & $\sqrt{ }$ & $\sqrt{ }$ & $\sqrt{ }$ & $\sqrt{ }$ & $\sqrt{ }$ & $\sqrt{ }$ & $\sqrt{ }$ \\
\hline CLED4 & $\sqrt{ }$ & $\sqrt{ }$ & $\sqrt{ }$ & $\sqrt{ }$ & $\sqrt{ }$ & $\sqrt{ }$ & $\sqrt{ }$ & $\sqrt{ }$ & $\sqrt{ }$ & $\sqrt{ }$ & $\sqrt{ }$ & $\sqrt{ }$ & $\sqrt{ }$ & $\sqrt{ }$ \\
\hline CLED5 & $\sqrt{ }$ & $\sqrt{ }$ & $\sqrt{ }$ & $\sqrt{ }$ & $\sqrt{ }$ & $\sqrt{ }$ & $\sqrt{ }$ & $\sqrt{ }$ & $\sqrt{ }$ & $\sqrt{ }$ & $\sqrt{ }$ & $\sqrt{ }$ & $\sqrt{ }$ & $\sqrt{ }$ \\
\hline CLED7 & $\sqrt{ }$ & $\sqrt{ }$ & $\sqrt{ }$ & $\sqrt{ }$ & $\sqrt{ }$ & & $\sqrt{ }$ & $\sqrt{ }$ & $\sqrt{ }$ & & $\sqrt{ }$ & $\sqrt{ }$ & $\sqrt{ }$ & $\sqrt{ }$ \\
\hline CLED8 & $\sqrt{ }$ & $\sqrt{ }$ & $\sqrt{ }$ & $\sqrt{ }$ & $\sqrt{ }$ & $\sqrt{ }$ & $\sqrt{ }$ & $\sqrt{ }$ & $\sqrt{ }$ & $\sqrt{ }$ & $\sqrt{ }$ & $\sqrt{ }$ & $\sqrt{ }$ & $\sqrt{ }$ \\
\hline CLED9 & & $\sqrt{ }$ & & $\sqrt{ }$ & $\sqrt{ }$ & $\sqrt{ }$ & $\sqrt{ }$ & $\sqrt{ }$ & $\sqrt{ }$ & $\sqrt{ }$ & $\sqrt{ }$ & $\sqrt{ }$ & $\sqrt{ }$ & $\sqrt{ }$ \\
\hline RLED1 & & & & & & $\sqrt{ }$ & & $\sqrt{ }$ & $\sqrt{ }$ & $\sqrt{ }$ & $\sqrt{ }$ & $\sqrt{ }$ & $\sqrt{ }$ & \\
\hline RLED2 & & & & & & & & & & & & & & \\
\hline RLED3 & & $\sqrt{ }$ & & $\sqrt{ }$ & $\sqrt{ }$ & & $\sqrt{ }$ & $\sqrt{ }$ & & $\sqrt{ }$ & $\sqrt{ }$ & $\sqrt{ }$ & $\sqrt{ }$ & \\
\hline RLED4 & & $\sqrt{ }$ & & $\sqrt{ }$ & $\sqrt{ }$ & $\sqrt{ }$ & $\sqrt{ }$ & $\sqrt{ }$ & $\sqrt{ }$ & $\sqrt{ }$ & $\sqrt{ }$ & $\sqrt{ }$ & $\sqrt{ }$ & \\
\hline SLED1 & & $\sqrt{ }$ & & $\sqrt{ }$ & $\sqrt{ }$ & $\sqrt{ }$ & $\sqrt{ }$ & $\sqrt{ }$ & & $\sqrt{ }$ & $\sqrt{ }$ & $\sqrt{ }$ & $\sqrt{ }$ & $\sqrt{ }$ \\
\hline \multicolumn{15}{|c|}{ Performance } \\
\hline CLED10 & & & $\sqrt{ }$ & $\sqrt{ }$ & & $\sqrt{ }$ & $\sqrt{ }$ & & & & $\sqrt{ }$ & & $\sqrt{ }$ & \\
\hline CLED11 & $\sqrt{ }$ & $\sqrt{ }$ & $\sqrt{ }$ & $\sqrt{ }$ & $\sqrt{ }$ & & $\sqrt{ }$ & & $\sqrt{ }$ & $\sqrt{ }$ & $\sqrt{ }$ & $\sqrt{ }$ & $\sqrt{ }$ & $\sqrt{ }$ \\
\hline CLED12 & $\sqrt{ }$ & & $\sqrt{ }$ & & & & $\sqrt{ }$ & & & $\sqrt{ }$ & $\sqrt{ }$ & $\sqrt{ }$ & $\sqrt{ }$ & $\sqrt{ }$ \\
\hline CLED13 & $\sqrt{ }$ & $\sqrt{ }$ & $\sqrt{ }$ & $\sqrt{ }$ & $\sqrt{ }$ & & $\sqrt{ }$ & & $\sqrt{ }$ & $\sqrt{ }$ & $\sqrt{ }$ & $\sqrt{ }$ & $\sqrt{ }$ & $\sqrt{ }$ \\
\hline RLED5 & & & & & & & & & & & & & & \\
\hline RLED6 & & & & & & & & & & $\sqrt{ }$ & $\sqrt{ }$ & $\sqrt{ }$ & $\sqrt{ }$ & $\sqrt{ }$ \\
\hline SLED2 & & & & & & & & & & & & & & \\
\hline \multicolumn{15}{|l|}{ Safety } \\
\hline CLED6 & $\sqrt{ }$ & $\sqrt{ }$ & $\sqrt{ }$ & $\sqrt{ }$ & $\sqrt{ }$ & $\sqrt{ }$ & $\sqrt{ }$ & $\sqrt{ }$ & $\sqrt{ }$ & $\sqrt{ }$ & $\sqrt{ }$ & $\sqrt{ }$ & $\sqrt{ }$ & $\sqrt{ }$ \\
\hline CLED14 & $\sqrt[V]{ }$ & $\sqrt{ }$ & $\sqrt{ }$ & $\sqrt{ }$ & $\sqrt{ }$ & $\sqrt{ }$ & $\sqrt{ }$ & $\sqrt{ }$ & $\sqrt{ }$ & $\sqrt{ }$ & $\sqrt{ }$ & $\sqrt{ }$ & $\sqrt{ }$ & $\sqrt[V]{ }$ \\
\hline CLED15 & & $\sqrt{ }$ & & $\sqrt{ }$ & $\sqrt{ }$ & & & & $\sqrt{ }$ & $\sqrt{ }$ & $\sqrt{ }$ & $\sqrt{ }$ & $\sqrt{ }$ & $\sqrt[V]{ }$ \\
\hline CLED16 & $\sqrt{ }$ & $\sqrt{ }$ & $\sqrt{ }$ & $\sqrt{ }$ & $\sqrt{ }$ & $\sqrt{ }$ & $\sqrt{ }$ & $\sqrt{ }$ & $\sqrt{ }$ & $\sqrt{ }$ & $\sqrt{ }$ & $\sqrt{ }$ & $\sqrt{ }$ & $\sqrt{ }$ \\
\hline CLED17 & $\sqrt{ }$ & $\sqrt{ }$ & $\sqrt{ }$ & $\sqrt{ }$ & $\sqrt{ }$ & $\sqrt{ }$ & $\sqrt{ }$ & $\sqrt{ }$ & $\sqrt{ }$ & $\sqrt{ }$ & $\sqrt{ }$ & $\sqrt{ }$ & $\sqrt{ }$ & $\sqrt{ }$ \\
\hline CLED18 & $\sqrt[V]{ }$ & $\sqrt{ }$ & $\sqrt{ }$ & $\sqrt{ }$ & $\sqrt{ }$ & & $\sqrt{ }$ & $\sqrt{ }$ & & $\sqrt{ }$ & $\sqrt[V]{ }$ & $\sqrt{ }$ & $\sqrt[V]{ }$ & $\sqrt{ }$ \\
\hline CLED19 & $\sqrt{ }$ & $\sqrt{ }$ & $\sqrt{ }$ & $\sqrt{ }$ & $\sqrt{ }$ & $\sqrt{ }$ & $\sqrt{ }$ & $\sqrt{ }$ & $\sqrt{ }$ & $\sqrt{ }$ & $\sqrt{ }$ & $\sqrt{ }$ & $\sqrt{ }$ & $\sqrt{ }$ \\
\hline $\begin{array}{l}\text { RLED7 } \\
\text { RLED8 }\end{array}$ & $\sqrt{ }$ & $\sqrt{ }$ & $\sqrt{ }$ & $\sqrt{ }$ & $\sqrt{ }$ & $\sqrt{ }$ & $\sqrt{ }$ & $\sqrt{ }$ & V & $\sqrt{ }$ & $\sqrt{ }$ & $\sqrt{ }$ & $\sqrt{ }$ & $V$ \\
\hline
\end{tabular}

an efficiency measures on the same conditions of $92 \mathrm{~lm} / \mathrm{W}$. This is over a $30 \%$ efficiency increment just based on the LED selection.

\subsection{Safety}

\subsubsection{Ecological aspects}

All the bulbs are RoHS rated by their manufacturers (CLED14).

\subsubsection{Protections against humidity or insect entrance}

In all the bulbs tested all the drivers were individually isolated. In 5 cases with a basic thermal rubber (CLED6) and in all the other with a thermal transmitter electrically isolated tape (RLED3).

However none of them have neither on the driver's electronic or in the LED matrix a resin protection cover for humidity or dust (RLED7).

Concerning the equivalent IP protection rate either the lamps did not meet the minimum protection (IP22 equivalent) due to holes on their body or pass the highest level prescribed (IP43 equivalent).

\subsubsection{Identification to avoid bad input power $A C / D C$ application}

All the bulbs presented a clear label where it is clearly indicated the nature of the input power voltage (CLED16).

\subsubsection{The devices must be tested to be safe in case of invert power input}

All the bulbs have a diode bridge in the power entrance so that they are not only inverse polarization protected but they are prepared to work independently of the polarization used (CLED17 \& RLED8).

\subsubsection{Protection against solar panel open circuit voltage}

Two bulbs ( 6 and 9 ) did not regulate properly the input power when applying a $21 \mathrm{~V}$ input voltage and thus the input current also increased in a way that the driver broke down after working a few seconds in this mode (CLED18).

\subsubsection{Low EMI generation}

The CC low voltage LED input power of the LEDs requires no power commutation that may generate a significant amount of EMI. The results of all the tests reflected no interaction with the radio emission reception. (CLED19).

\subsection{Summary of results}

Table 5 summarizes all the results of the tests done with the test bulb set to easily verify the new requirement accomplishments of each unit.

Only 2 bulbs accomplished all the compulsory requirements established, although 4 models failed only in 1 compulsory field and 3 more in 2 fields of this segment. Many recommended point were achieved and just one suggested aspect was reached by a few lamps. Most of the failures detected in compulsory requirements are caused by a bad quality non-lighting rated LED and body material choices and inefficiencies in their manufacturing processes.

About the performance requirements, many bulbs do not stand an overvoltage input closed to the shot circuit solar panel voltages, and some drivers do not work properly on extreme ambient temperature. 
The main problems with the safety requirements are related to the protection against humidity and insect entrance. Most of the LED bulbs compromise the seal of the electronic components to create some air conduction pipes to improve heat dissipation based on the supposition that these devices will be placed inside a higher protection luminaire [75].

All the measure units and instruments used for the tests proposed can be bought and built for a little less than $1.000 €$ if the temperatures are measured with contact sensors or infrared sensors with laser targeting devices (that cost around $35 €$ ). If a thermograph camera is acquired, the budget raise to about $2.000 €$

\section{Conclusions}

With the new LED lighting devices new possibilities are open for SHS. However, it is necessary to establish the required specifications and tests to evaluate their real quality before using them on the specific operational conditions of real PVRE projects. This is very important in order to guarantee the performance of the devices through the measurement of a list of technical parameters organized on 3 main groups: reliability, performance and safety.

Following the same philosophy of the existing Universal Technical Standard for Solar Home System [25] we have proposed 19 compulsory, 8 recommended and 2 suggested technical specifications and their corresponding quality control procedures for DC LED bulbs using non sophisticated, affordable or own-made measure equipment. These requirements are the result of the combination of a deep review of the many standards existing, the technical specifications of the manufactures of this technology and many scientific publications. This information is contrasted with the compilation of experiences after the evaluation of many SHS PV rural electrification programs with CFLs (and all the problems reported in these installations).

This proposal has been applied to a representative sample of 14 low cost LED bulbs suitable for PV SHS projects in developing countries and the results have been presented. The summary of the test results is that 2 of these LED bulbs comply with all the compulsory specifications and, consequently, would be accepted in a hypothetical process of selection for a PVRE program. On the other hand, it is important to remark that 7 more bulbs tested failed only one ( 4 models) or two ( 3 models) of the 18 compulsory requirements and probably could easily pass that fails trough simple corrections.

Moreover, nowadays very few recommended and suggested items are achieved as, in the best case, only half of the recommended requirements are passed. However, LED bulbs are a recent technology and low-cost devices are just starting to appear in the market. It is expected that by the time this work is published many more low cost LED bulbs could easily fulfill all the compulsory requirements and many of the recommended and suggested while prices will be steadily reduced due to massive productions and the consolidation of the technology in the market [76,77].

\section{Acknowledgment}

The authors wish to thank Dr. Eduardo Lorenzo Pigueiras, full professor of the Universidad Politécnica de Madrid, for his valuable comments to this work.

\section{References}

[1] Bessho M, Shimizu K. Latest trends in LED lighting. Electron Commun Jpn 2012;95:1-7.
[2] Pode R. Financing LED solar home systems in developing countries. Renew Sustain Energy Rev 2013;25:596-629.

[3] Energy saving potential of solid state lighting general illumination applications. United State Department of Energy, 〈http://apps 1.eere.energy.gov/build ings/publications/pdfs/ssl/ssl_energy_savi_ntial_final.pdf); 2010.

[4] Solid-state lighting research and development: Multiyear program. Lighting research and development building technologies program. hhttp://apps1.eere. energy.gov/buildings/publications/pdfs/ssl/ssl_mypp2012_web.pdf); April 2012.

[5] Pode R. Solution to enhance the acceptability of solar-powered LED lighting technology. Renew Sustain Energy Rev 2010;14(3): 1096-103.

[6] Lim SR, Kang D, Ogunseitan OA, Schoenung IM. Potential environmenta impacts from the metals in incandescent, compact fluorescent lamp (CFL), and light-emitting diode (LED) bulbs. Environ Sci Technol 2012;47(2):1040-7.

[7] Lim SR, Kang D, Ogunseitan OA, Schoenung JM. Potential environmental impacts of light-emitting diodes (LEDs): metallic resources, toxicity, and hazardous waste classification. Environ Sci Technol 2010;45(1):320-7.

[8] Samson M. Reclaiming reusable and recyclable materials in Africa. A critical review of English language literature. Women in Informal Employment: Globalizing and Organizing (WIEGO), (http://wiego.org/sites/wiego.org/files/ publications/files/Samson_WIEGO_WP16.pdf); 2010.

[9] Verderber RR, Morse OC, Rubinstein FM. Performance of electronic ballast and controls with 34- and 40-W F40 fluorescent lamps. IEEE Trans Appl Ind $1989 ; 25(6): 1049-59$.

[10] Zilles R, Lorenzo E, Serpa P. From candles to PV electricity: a four-year experience at Iguape-Cananeia, Brasil. Prog Photovolt 2000;8(4):421-34.

[11] Nieuwenhout FDJ, Van de Rijt PJNM, Wiggelinkhuizen EJ, Van der Plas RJ. Rural lighting services: a comparison of lamps for domestic lighting in developing countries. In: Proceedings of the 2 nd world conference on photovoltaic solar energy conversion, Vienna; 1998 . p. 3086-9.

[12] Narvarte L, Muñoz J, Lorenzo E. Testing of Fluorescent DC Lamps for SHSs. Prog Photovolt $2001 ; 9(6): 475-89$.

[13] IEA. World Energy Outlook 2011: OECD/IEA /http://www.iea.org/publications/ freepublications/publication/WEO2011_WEB.pdf); 2011.

[14] Africa, Lighting. Solar lighting for the base of the pyramid: overview of an emerging market. Lighting Africa, a joint initiative from IFC and the World Bank, (http://www.ifc.org/wps/wcm/connect/a68a120048fd175eb8dcbc849537832d/ SolarLightingBasePyramid.pdf?MOD=AJPERES $>2010$.

[15] Posorski R, Fahlenbock B. Technical standards and tender specifications for Solar Home Systems and PV supply of rural health stations in developing countries. In: Proceedings of the 2 nd world conference on photovoltaic solar energy conversion, Vienna; 1998. p. 2859-63.

[16] Wilshaw AR, Bates JR, Oldach R. Review of Standards and quality assurance schemes for PV systems. In: Proceedings of the 16th European PV solar energy conference; 2000.

[17] Kenya rural enterprise programme, draft components and installation standards, energy alternatives AFRICA, Kenya; 1997.

[18] Model of technical specification for Solar Home Lighting Systems, Indian Renewable Energy Development Agency (IREDA), India; 1997.

[19] Specifications for Solar Home Systems, Solar Power \& Light Co. Ltd., Sri Lanka; 1997.

[20] Specifications for Solar Home Systems. World Bank-ASTAE-BPP Teknologi, Indonesia; 1996.

[21] Basic electrification for rural households, GTZ, Eschborn; 1995.

[22] Standard technical specification for the supply of photovoltaic systems equipment for Solar Homes ESKOM, South Africa; 1997.

[23] Especificación Técnica para Sistemas Fotovoltaicos de lluminación Doméstica Rural, Instituto de Investigaciones Eléctricas (IIE), Mexico; 1992

[24] DC Fluorescent Light Testing Procedure, Project Management Office. World Bank/GEF Assisted China Renewable Energy Development Project, China; 1999.

[25] Universal Technical Standard for Solar Home Systems, Thermie B: SUP-995-96, EC-DGXVII, V2, Luxembourg: Office for Official Publications of the European Communities; 2001.

[26] Programa de Infraestructura Descentralizada para la Transformación Rural World Bank, Contract Lumber 3788; $\langle$ http://www.pevd.gob.bo/ $\rangle$.

[27] International Open Tender LPI 002/2005. Suministro de Servicios de Electricidad con Sistemas Fotovoltaicos. Bolivia; 2005.

[28] Reglamento Técnico, Especificaciones Técnicas y Procedimientos de Evaluación del Sistema Fotovoltaico y sus Componentes para Electrificación Rural. R.D. N ${ }^{\circ}$ 003-2007-EM/DGE; 2007.

[29] Lighting Industry Liaison Group. A Guide to the Specification of LED Lighting Products, 〈http://www.npl.co.uk/upload/pdf/led-lighting-spec-2012.pdf); 2012.

[30] California energy commission, Voluntary California quality light emitting diode (LED) lamp specification. CEC-400-2012-016-SF, http://www.energy. ca.gov/2012publications/CEC-400-2012-016/CEC-400-2012-016-SF.pdf); December 2012.

[31] Energy Star. ENERGY STAR(B) Program Requirements for Integral LED Lamps, 〈http://www.energystar.gov/ia/partners/product_specs/program_reqs/Inte gral_LED_Lamps_Program_Requirements.pdf); 2011.

[32] Manitoba. Commercial Lighting Program. Technical specification guide, htttps://www.hydro.mb.ca/your_business/lighting/information_sheets/techni cal_spec guide.pdf $; 2013$.

[33] Government of India. Ministry of Railways. Functional requirement specification for energy based luminaire unit for indoor lights to be used in Indian railway offices and building. Research Designs \& Standards Organization, 
Manak Nagar, Lucknow 226-011, 〈http://www.rdso.indianrailways.gov.in/ uploads/File/110426_FRS_LED_Indoor_lighting_specifications_EOI(1).pdf).

[34] Mills E. Product quality assurance for off-grid lighting in Africa. Lawrence Berkeley National Laboratory. In: Conference Proceedings from the lighting Africa product quality assuance worksop, Arlie Va; 2008.

[35] Mohanty P, Sharma A, Thakur N, Sharma KR, Chaurey A. Laboratory and field based integrated approach for assessing performance and utilization of LED Solar Lanterns in rural areas. In: Proceedings of the IEEE international conference on advances in power conversion and energy technologies (APCET); 2012. p. 1-8.

[36] Bopp G, Lux S, Pfanner N, Strasser M, Wiezorek C, Muller M. Stand-alone LED lighting systems quality screening, lighting Africa, World Bank. Final Report Part III, hhttp://lightingafricaconference.org/fileadmin/user upload/Documents/ Briefing_Notes_Lifetime_April_2010_Issue2.pdf); June 2010.

[37] Illuminating Engineering Society, IES LM-80-08 Measuring Lumen Maintenance of LED Light Sources; 2008. ISBN: 978-0-87995-227-3.

[38] Müggenburg H, Tillmans A, Schweizer-Ries P, Raabe T, Adelmann P. Social acceptance of PicoPV systems as a means of rural electrification - a sociotechnical case study in Ethiopia. Energy Sustain Dev 2012;16(1):90-7.

[39] Hansen UE, Pedersen MB, Nygaard I. Review of Solar PV market development in East Africa. In: 1st Africa photovoltaic solar energy conference and exhibition proceedings, Durban, South Africa; 27-29 March 2014.

[40] Hellpap C, de Haan D. How can PicoPV contribute to sustainable energy for all? In: Proceedings of the 3rd symposium on small PV-applications, Ulm Germany, June 17-18 2013.

[41] Horn M, Verástegui A. Experiences with Pico PV in Peru. In: Proceedings of the 3rd symposium on small PV-applications, Ulm Germany, June 17-18 2013.

[42] Samuel T, Baillot R, Vervaart M. Innovative street lighting solution for rural electrification. In: Proceedings of the 3rd symposium on small PV-applications, Ulm Germany, June 17-18 2013.

[43] Mahlia TMI, Saktisahdan T], Jannifar A, Hasan MH, Matseelar HSC. A review of available methods and development on energy storage; technology update. Renew Sustain Energy Rev 2014;33:532-45.

[44] Lahimer AA, Alghoul MA, Yousif F, Razykov TM, Amin N, Sopian K. Research and development aspects on decentralized electrification options for rural household. Renew Sustain Energy Rev 2013;24:314-24.

[45] CREE, Cree XLamp Long-Term Lumen Maintenance, Application note: CLDAP28 Rev 2, /http://www.cree.com/ /media/Files/Cree/LED\%20Components\% 20 and\%20Modules/XLamp/XLamp\%20Application\%20Notes/XLamp_lumen_ maintenance.pdf; April 2013.

[46] Philips solid-state lighting solutions. Understanding LM-80, Lumen maintenance, and LED fixture lifetime. Technical Brief BRO-000028-07 R00, 〈http:// www.colorkinetics.com/support/whitepapers/ledlifetime.pdf); February 2010.

[47] Fan J Yung KC, Pecht M. Lifetime estimation of high-power white LED using the degradation-data-driven method. Trans Device Mater Reliab 2012:12 (2): $470-7$.

[48] Li DS, Zou NY, Zhang YC, He XY, Yang Y. Study of High-Power White LED's lifetime based on accelerated life test. Adv Mater Res 2013:800:205-9.

[49] Liu DJ, Yang DG, Cai M, Wu BY, Yang X, Liu J, et al. Effect of temperature and voltage on LED luminaries reliability. Int J Mater Struct Integr 2012;6 (2):270-83.

[50] Li XP, Chen L, Chen M. An approach of LED lamp system lifetime prediction. In: Proceedings of the 2011 IEEE international conference on quality and reliability (ICQR), September 2011. p. 110-4.

[51] Tao G. Trends and challenges in solid state lighting reliability. In: Proceedings of the 20th IEEE international symposium on the physical and failure analysis of integrated circuits (IPFA), July 2013. p. 299-302.

[52] Narendran N, Deng L. Proceedings of the IESNA Annual Conference, Salt Lake City, Utah, August 4-7, 2002. p. 157-64.

[53] Tsai MY, Chen CH, Kang CS. Thermal measurements and analyses of low-cost high-power LED packages and their modules. Microelectron Reliab 2012;52 (5):845-54.

[54] Meneghini M, Dal Lago M, Trivellin N, Mura G, Vanzi M, Meneghesso G, et al. Chip and package-related degradation of high power white LEDs. Microelectron Reliab 2012;52(5):804-12.
[55] Su YF, Yang SY, Hung TY, Lee CC, Chiang KN. Light degradation test and design of thermal performance for high-power light-emitting diodes. Microelectron Reliab 2012;52(5):794-803.

[56] Jakovenko J, Formánek J, Perpiñà X, Jorda X, Vellvehí M, Werkhoven RJ, et al. Design methodologies for reliability of SSL LED boards. Microelectron Reliab 2013:53(8):1076-83.

[57] Kobayashi T, Itami D, Hashimoto R, Takashina T, Kanematsu H, Mizuta K, et al. Optimizing structure of LED light bulb for heat transfer. In: Journal of Physics: Conference Series 2013; 433(1): p. 012016

[58] Huaiyu Y, Koh S, van Zeijl H, Gielen AW], Guoqi Z. A review of passive themal management of LED module. J Semicond 2011;32(1):014008.

[59] Tarashioon S, Baiano A, van Zeijl H, Guo C, Koh SW, van Driel WD, et al. An approach to "Design for Reliability" in solid state lighting systems at high temperatures. Microelectron Reliab 2012;52(5):783-93.

[60] Chang MH, Das D, Varde PV, Pecht M. Light emitting diodes reliability review. Microelectron Reliab 2012:52(5):762-82.

[61] U.S. Department of Energy. Energy Efficiency of LEDs. Solid-state lighting technology fact sheet. Building technologies program. Energy, Efficiency and renewable energy. PNNL-SA-94206, 〈http://apps1.eere.energy.gov/buildings/ publications/pdfs/ssl/led_energy_efficiency.pdf); March 2013.

[62] Scholand MJ, Dillon HE. Life-cycle assessment of energy and environmenta impact of LED lighting products. Part 2: LED manufacturing and performance. U.S. Department of Enegy. Solid-state lighting program, http://apps1.eere. energy.gov/buildings/publications/pdfs/ssl/lca_factsheet_apr2013.pdf); June 2012 .

[63] Harish SM, Raghavan SV, Kandlikar M, Shrimali G. Assessing the impact of the transition to Light Emitting Diodes based solar lighting systems in India. Eng Sustain Dev 2013;17(4):363-70.

[64] Panahi A. Challenges and opportunities in LED based lighting. In: Proceedings of the SPIE 8720, Photonic Applications for Aerospace, Commercial, and Harsh Environments IV; May 31, 2013.

[65] Lighting global, minimum quality standards and recommended performance targets for lighting global, lighting Africa, and lighting Asia, 〈http://www. lightingafrica.org/component/docman/doc download/448-2013-stds-targetsstakeholder-memo.html; June 7, 2013

[66] Dalrymple 1, Wright N, Kellner R, Bains N, Geraghty K, Goosey M, et al. An integrated approach to electronic waste (WEEE) recycling. Circuit World $2007 ; 33(2): 52-8$

[67] NEMA. ANSI/IEC 60529-2004. Degrees of protection provided by enclosures (IP\&Code). Rosslyn: National Electrical Manufacturers Association; 2004

[68] Mink T, Alstone P, Tracy J, Jacobson A. LED flashlights in the Kenyan market: quality problems confirmed by laboratory testing. Prepared for Lighting Africa, IFC and World Bank; 2010.

69] Sera D, Teodorescu R, Rodriguez P. PV panel model based on datasheet values. In: Procedings of the IEEE international symposium on industrial electronics, ISIE 2007; 2007. p. 2392-6.

[70] Tsai HC. An investigation on the influence of electromagnetic interference induced in conducting wire of universal LEDs. Microelectron Reliab 2007;47 (6):959-66.

71] Egido MA, Lorenzo E, Narvarte L. Universal technical standard for Solar Home Systems. Prog Photovolt 1998;6(5):315-24.

[72] Chou HY, Chen CC, Yang TH. Maintenance of stable light emission in high power LEDs. Microelectron Reliab 2012;52(5):912-5.

[73] Muñoz-Martínez VF, Serón-Barba J, Molina-Mesa R, Gómez-de-Gabriel JM, Fernández-Lozano J, García-Cerezo A. Double reflection goniophotometer. Metrologia 2006;43(3):185.

[74] Cree, Xlamp@ mX-6 leds, Product family data sheet. CLD-DS23 Rev 7B, (http:/ www.cree.com/LED-Components-and-Modules/Products/XLamp/Discrete-Dir ectional/XLamp-MX6); 2013

[75] Wang ZB, Zhang YB, Wang ZD, Xie SS, Hao Y. Heat pipe heat sink of high power LED based on thermal resistance network. J Appl Opt 2012;6:005

[76] Haitz R, Tsao JY. Solid state lighting: "The case" 10 years after and future prospects. Phys Status Solidi A 2011;208(1):17-29.

[77] Karlicek RF. Future directions in LED applications. Therm Manag LED Appl 2014;2:519-41. 